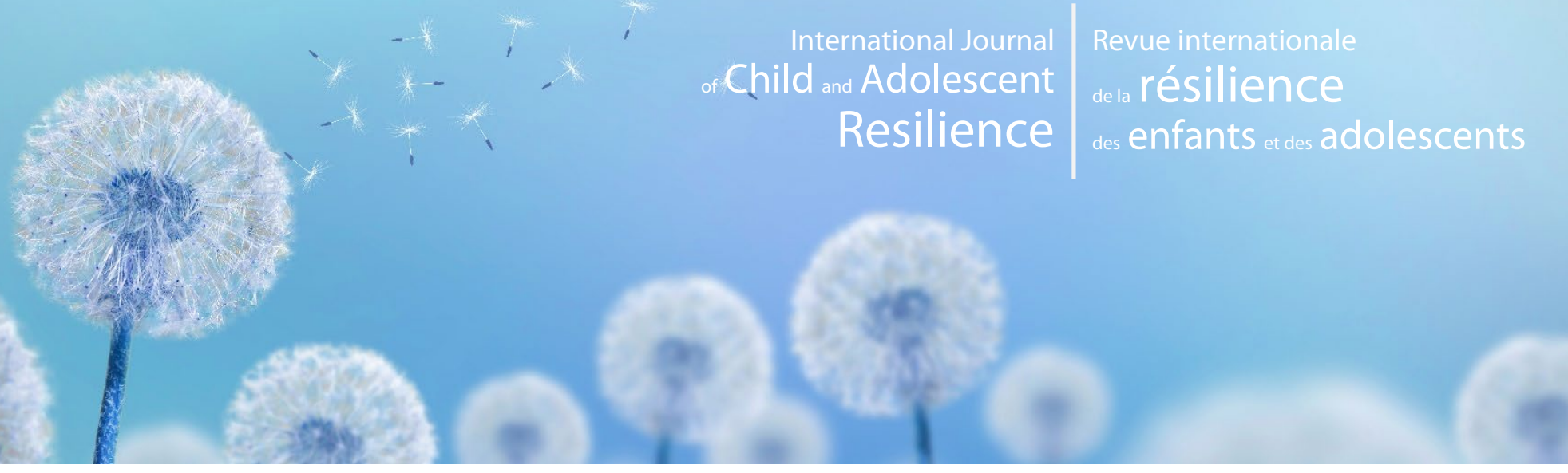

\title{
A conceptual model of the intergenerational transmission of emotion dysregulation in mothers with a history of childhood maltreatment
}

\section{Sarah J. CABECINHA-ALATI', Rachel LANGEVIN', and Tina C. MONTREUIL ${ }^{2}$}

\footnotetext{
1 Department of Educational and Counselling Psychology, McGill University

2 Department of Psychiatry, McGill University
}

Corresponding Author: Rachel Langevin, Department of Educational and Counselling Psychology, McGill University, 3700 McTavish St. room 614, Montreal, Québec, Canada H3A 1 Y2.

Email: rachel.langevin@mcgill.ca.

\section{Abstract}

Objectives: Adults with a history of childhood maltreatment report problems with emotion regulation (ER) and parenting, which can contribute to maladaptive outcomes in offspring. The following narrative review consists of a theoretical and empirical synthesis of the literature examining child maltreatment, emotion regulation, and parenting, with an emphasis on parental emotion socialization.

Method: Building upon the literature contained in the review, we developed a novel conceptual model that elucidates some of the mechanisms involved in the intergenerational transmission of emotion dysregulation among mothers with a history of childhood maltreatment. Taking into account risk and protective factors (e.g., socio-economic status, polyvictimization, teenage motherhood, access to social supports), our conceptual model highlights both direct (e.g., social learning) and indirect (e.g., ER difficulties) mechanisms through which child maltreatment contributes to problems with parental emotion socialization and ER difficulties in the next generation.

Implications: Directions for future research and implications for intervention will be discussed with an emphasis on preventing the continuity of maladaptive parenting by promoting the development of parents' ER abilities in a traumainformed, resilience-focused framework.

Keywords: Intergenerational transmission; emotion socialization; parent-child relationships; childhood maltreatment; emotion dysregulation. 


\section{Introduction}

Child maltreatment is defined as any act of commission or omission by a parent or caregiver that results in harm, potential for harm, or threat of harm to a child under the age of 18. The most commonly recognized forms of child maltreatment include physical abuse, sexual abuse, emotional maltreatment, and neglect (Leeb et al., 2008). In Ontario, which is the most populated province in Canada (Statistics Canada, 2019), approximately 6.29\% of children were involved in maltreatment-related investigations in 2018, with over 148,000 investigations occurring that year (Fallon et al., 2020). Of these investigations, 26\% were substantiated ${ }^{1}$ for reasons of neglect (21\%), physical abuse (19\%), emotional maltreatment (12\%), and sexual abuse (3\%). Furthermore, although reports of childhood physical (26\%) and sexual (8\%) abuse are prevalent among Canadian adults, 93\% of those surveyed indicated that they did not report the abuse to police or child protective services before age 15 and the majority (67\%) indicated that they never reported the abuse to anyone (Burczycka, 2017). As such, the prevalence of child maltreatment in Canada is likely underestimated.

\section{The impact of child maltreatment on emotion regulation}

The negative impact of child maltreatment on mental health is well-documented as numerous studies have identified a link between abusive childhood experiences and adult psychopathology including depression, anxiety, posttraumatic stress, dissociation, substance use, and personality disorders (see Kessler et al., 2010 and Weich et al., 2009 for reviews). To explain the association between child maltreatment and these adverse outcomes, Cloitre, Cohen, and Koenen (2011) proposed the Resource Loss Model of Childhood Abuse Trauma wherein the short- and long-term effects of child maltreatment can be understood as a consequence of the resources that are lost when abuse or neglect is perpetrated by a caregiver. According to this model, resource losses - such as the loss of a healthy attachment relationship with one's primary caregiver - can compromise the attainment of developmental tasks that are intrinsic to childhood, resulting in impairments that accumulate into adulthood. The acquisition of ER is a key developmental task in childhood (Eisenberg \& Morris, 2002) and the ability to regulate emotions is developed mainly through interactions with attachment figures who are typically the child's primary caregivers (Schore \& Schore, 2008).

Shifting away from Bowlby's (1969) and Ainsworth's (1969) descriptions of attachment theory, which originated in the era of behaviourism, Schore and Schore (2008) proposed that modern attachment theory should be conceptualized a theory of affect regulation. In this framework, the primary caregiver must be attuned to dynamic shifts in the infant's internal states and appraise non-verbal expressions of the infant's arousal. In turn, the caregiver's level of sensitivity and responsiveness to these cues mediates the dyadic regulation of emotions and sets the foundation for a secure attachment relationship. The "good-enough caregiver" who has become mis-attuned can engage in interactive repair and act as a resource for emotional co-regulation if they are able to re-attune in a timely and consistent manner. However, when the primary caregiver is abusive or neglectful, circumstances of maltreatment disrupt this attachment relationship because the caregiver, who traditionally acts as a resource for safety and co-regulation is also a source of danger and dysregulation, which can lead to insecure, disorganized attachment (Cloitre, Cohen, \& Koenen, 2011; Schore \& Schore, 2008). In cases of child maltreatment, or complex trauma, the trauma is chronic, interpersonal, and embedded in the child's caregiving system (van der Kolk, 1996; van der Kolk, 2005). The relational stress engendered by this trauma can compromise the experience-dependent maturation of developing brain areas that are critical to ER (Schore \& Schore, 2008). Further, emotional guidance from a caregiver who is neglectful, physically, or sexually abusive is often absent, irregular, or deviant (Cloitre, Cohen, \& Koenen, 2011). Thus, in the absence of a healthy attachment relationship with another caregiver, a child who is maltreated is not provided with the emotional attunement or scaffolding that would enable them to regulate their arousal (Cicchetti \& Toth, 2005; Kim \& Cicchetti, 2010), thereby disrupting the development of self-regulation.

Child maltreatment, emotion regulation, and psychopathology in youth. Child maltreatment has been associated with ER difficulties in childhood including emotional lability (Shipman et al., 2000; 2007), lower levels of emotional understanding, empathy, and emotional self-awareness (Perlman et al., 2008; Shipman et al., 2000; 2005), dysregulated emotional expressions (Maughan \& Cicchetti, 2002; Shipman \& Zeman, 2001), and difficulties identifying negative emotions (Pollak et al., 2000). However, there seems to be an exception amongst physically abused children, who show enhancements in the ability to detect angry faces (Ardizzi et al., 2015; Masten et. al., 2008). Although this acuity might be advantageous in environments that require children to be vigilant toward potential threats, attentional

\footnotetext{
1 The remaining $45 \%$ were substantiated for exposure to intimate partner violence, which was not included in the present review.
} 
biases toward angry faces have been linked to increases in negative affect and aggressive behaviours that put children at risk for externalizing problems (Shackman \& Pollack, 2014). Emotion dysregulation has been identified as a predictor of externalizing and internalizing problems in maltreated children (Muller et al., 2013) and mediates the relationship between child maltreatment and psychopathology in childhood (Alink et al., 2009; Kim \& Cicchetti, 2010) and adolescence (Heleniak et al., 2016; Moretti \& Craig, 2013). Thus, child maltreatment appears to put youth at risk for ER difficulties that contribute to the development of psychopathology.

Child maltreatment, emotion regulation, and psychopathology in adults. In addition to studies focusing on youth, a growing body of literature explores the long-term impacts of child maltreatment on adult ER. For example, women who reported sexual, physical, or emotional abuse in childhood reported higher levels of ER difficulties (Burns et al., 2010), such as experiential avoidance and emotional non-acceptance, compared to those who experienced low levels of abuse or no abuse (Gratz et al., 2007). Adults with a history of child maltreatment also exhibit generalized dysregulation in the biological systems associated with stress response (Heim et al., 2000; van Voorhees \& Scarpa, 2004) as well as deficits in the coordination of cognitive and affective brain circuits that underlie ER (Caldwell et al., 2014). Specifically, early abuse can result in sensitization of the hypothalamic-pituitary-adrenal (HPA) axis, which can increase one's vulnerability to the adverse effects of stress and contribute to a predisposition towards psychopathology (Heim et al., 2000; van Voorhees \& Scarpa, 2004). Similarly, the ability to regulate stress and negative affect is contingent upon flexible communication between the prefrontal cortex and limbic system, which appears to be compromised in adults who are maltreated as children (Caldwell et al., 2014).

Relative to other types of trauma, the consequences of child maltreatment are thought to be particularly detrimental to emotional functioning because of its early onset and interpersonal nature (see Freyd, 1996 for Betrayal Trauma Theory and van der Kolk, 2005 for Developmental Trauma Disorder). Compared to survivors of noninterpersonal traumas and traumas that were perpetrated in adulthood, adults who experienced early-onset interpersonal traumas reported more problems tolerating and managing negative emotions, a lack of emotional clarity, and had more troubles overcoming negative emotions that interfered with goal-directed behaviour (Briere \& Rickards, 2007; Ehring \& Quack, 2010). Furthermore, higher levels of exposure to betrayal traumas (i.e., traumas perpetrated by someone the victim was close with) predicted greater levels of alexithymia, anxiety, and depression in undergraduate students (Goldsmith et al., 2012). Thus, the early onset of child maltreatment, as well as the feelings of betrayal that are engendered by this type of trauma, can disrupt emotional development in ways that increase the risk of psychopathology in adulthood.

In support of this notion, ER difficulties have consistently been identified as a mediator in the relationship between child maltreatment and adult mental health problems including posttraumatic stress disorder (PTSD; Barlow et al., 2017; Burns et al., 2010), depression (Crow et al., 2014; Hopfinger et al., 2016), borderline personality disorder (Gratz et al., 2008), anxiety (Huh et al., 2017), and psychological distress more broadly (Rosenthal et al., 2005). There is also research that suggests that the indirect effects of ER difficulties on psychopathology in adulthood may be specific to high betrayal traumas (Goldsmith et al., 2013). These findings coincide with the increasing recognition that ER is a transdiagnostic factor in psychopathology (Aldao et al., 2010; Gross \& Jazaieri, 2014) as well as advances in attachment theory and affective neuroscience, which suggest that early abuse can have long-lasting impacts on the developmental trajectory of the right brain (Schore, 2002). Indeed, studies examining brain regions associated with emotional processing suggest that adults with a history of child maltreatment display altered patterns of reactivity and attentional biases toward negative facial expressions such as fear, anger, and sadness (Dannlowski et al., 2012; 2013; Gibb et al., 2009; van den Berg et al., 2019) in the absence of, and when controlling for, symptoms of psychopathology. Similarly, the relationships between child maltreatment, $E R$, and functional impairment appear robust, even when controlling for symptoms of PTSD (Ehring \& Quack, 2010; Cloitre et al., 2005).

Protective factors. Despite the well-established relationships between child maltreatment, ER difficulties, and psychopathology, a history of child maltreatment does not guarantee that people will experience mental health problems. Indeed, many abused individuals exhibit minimal levels of impairment as adults (Collishaw et al., 2007; DuMont et al., 2007) and can be classified as resilient. Evidence suggests that a secure pattern of relatedness with one's caregiver (Alink et al., 2009), the involvement of at least one supportive parent (Kooiman et al., 2004) or partner (DuMont et al., 2007), and the quality of one's peer and intimate relationships in adulthood (Collishaw et al., 2007), may buffer against the development of emotional and psychological difficulties in survivors of child maltreatment. As such, protective factors must also be considered when attempting to elucidate the effects of child maltreatment on ER in 
adulthood, as well as the effects of child maltreatment on parenting, which will be elaborated upon in the following section.

\section{Child maltreatment and parenting problems}

Concomitant with an increased risk for psychopathology and elevated rates of ER difficulties, another challenge faced by adult survivors of child maltreatment are difficulties in the parental role. In a systematic review of 12 studies that encompassed over 45,000 mother-child dyads, Plant and colleagues (2018) found strong evidence for a relationship between mothers' child maltreatment history and emotional and behavioural difficulties in offspring. Further, maternal psychological distress and poor parenting were identified as key mechanisms that explained these associations (Plant et al., 2018).

Numerous studies have identified links between child maltreatment and parenting problems including lower perceived competence (Bailey et al., 2012; Caldwell et al., 2011; Fitzgerald et al., 2005; Schuetze \& Eiden, 2005), reductions in maternal sensitivity, responsivity, and empathy (Bert et al., 2009; Fuchs et al., 2015; Lyons-Ruth \& Block, 1996; Pereira et al., 2012; Zvara, Meltzer-Brody, et al., 2017), increased use of harsh or physically punitive discipline (DiLillo et al., 2000; Schuetze \& Eiden, 2005), and higher levels of hostile or intrusive behaviours (Bailey et al., 2012; Lyons-Ruth \& Block, 1996; Moehler et al., 2007). Parents who were maltreated as children also exhibit inconsistent parenting behaviours (Collin-Vezina et al., 2005; Driscoll \& Easterbrooks, 2007), and report higher levels of parenting stress (Bai \& Han, 2016; Pereira et al., 2012).

However, not every study supports the associations between child maltreatment and parenting problems. For example, despite lower levels of self-reported parenting competence, some observational studies have shown that interactive behaviours are not always compromised when there is a maternal history of child maltreatment (e.g., Bailey et al., 2012; Fitzgerald et al., 2005; Sexton et al., 2017). When considering studies that have identified links between child maltreatment and poor parenting, the vast majority are composed of samples characterized by other risk factors, including participants who are younger in maternal age or with high rates of poverty and psychopathology (see Vaillancourt et al., 2017 for review). In contrast, studies that have not reproduced these associations tend to be composed of non-clinical samples (e.g., Fitzgerald et al., 2005; Sexton et al., 2017).

The impact of cumulative trauma and revictimization. Notwithstanding some contradictory findings, three systematic reviews have provided tentative support for the relationship between child maltreatment and later parenting problems (Hughes \& Cossar, 2016; Hugill et al., 2017; Vaillancourt et al., 2017). Longitudinal studies also support these associations and highlight the importance of considering the cumulative impact of child maltreatment on parenting. For example, a study of 1,994 mothers followed from pregnancy until their children were 3 years of age, found that cumulative childhood adversity was positively associated with maternal mental health problems and parenting concerns, as well as mothers' use of maladaptive coping strategies (McDonald et al., 2019). In addition, Banyard and colleagues (2003) found that higher rates of trauma exposure in childhood and adulthood were associated with lower parenting satisfaction and maladaptive parenting as evidenced by higher rates of physical punishment, child neglect, and protective services reports. Interestingly, the traumas that made the most significant contribution to negative parenting were ones that had occurred in adulthood, which the authors interpreted in light of the high rates of revictimization that are prevalent amongst survivors of child maltreatment (Arias, 2004; Desai et al., 2002). Banyard and colleagues (2003) suggested that a history of child maltreatment puts individuals at risk for experiencing additional traumas (e.g., intimate partner violence), which have a more proximal effect on parenting. In support of this notion, the experience of cumulative interpersonal traumas in childhood and adulthood has been associated with more negative parenting practices, even when controlling for demographic and diagnostic variables (Cohen et al., 2008) and when results are compared to individuals with no history of victimization or a history of victimization that occurred exclusively in childhood (Dubowitz et al., 2001). Thus, experiences of adult revictimization may exacerbate, or even account for, parenting difficulties amongst survivors of child maltreatment.

Protective factors. Although childhood trauma and revictimization may have a negative impact on parenting, engagement in resilient or positive parenting is still possible in spite of one's maltreatment history. For example, in a subsample of survivors who had experienced traumatic events in childhood and adulthood, greater connection to social supports and the ability to engage in self-care were protective factors associated with lower levels of parenting problems (Banyard et al., 2003). Similarly, parents who were able to break intergenerational cycles of maltreatment reported using various strategies to heal from their traumas including finding meaning in the aftermath of their traumatic experiences, engaging in conscious efforts to "parent differently", and relying on social, spiritual, or 
psychological supports (Chamberlain et al., 2019). They were also less likely to live with their families of origin and rely on their own mothers for emotional support (Easterbrooks et al., 2011). Consequently, breaking the cycle of maladaptive parenting may also be contingent upon the ability to disengage from people or contexts that perpetuate emotional distress and negative parenting behaviours.

\section{Child maltreatment history and parenting - The role of emotion regulation}

Amongst maltreated parents who perpetuate cycles of maladaptive parenting, extant literature suggests that a maternal history of abuse may have indirect effects on caregiving through its effect on mediating variables such as parental stress and depressive symptoms (see Vaillancourt et al., 2017 for review). Compared to mothers with no abuse histories, mothers who have experienced child maltreatment are at an increased risk for stress-related psychopathologies that impact parenting including post-partum depression (Beeghly et al., 2003; Talmon et al., 2019), anxiety (Buist et al., 2011; Madigan et al., 2014), PTSD (Muzik, Bocknek, et al., 2013; Muzik et al., 2016), and dissociation (Marysko et al., 2010). Additionally, borderline personality disorder and substance use problems, which are both associated with a history of child maltreatment (Elliot et al., 2014; Huang et al., 2011), have been linked to poor parenting (Florange \& Herpertz, 2019; Locke \& Newcomb, 2004).

The associations between child maltreatment and parenting problems may also be attributable to parental ER difficulties (Bailey et al., 2012; Ehrensaft et al., 2015). The ability to regulate emotions has been recognized as a crucial component of effective parenting since Dix (1991) proposed the Affective Organization of Parenting model. In this model, the processes parents use to understand and regulate emotions are of paramount importance because the parent's ability to engage in self-regulation is thought to facilitate the modulation of their own negative arousal, which in turn, enhances the ability to engage in sensitive and responsive parenting behaviours. Several studies have found that mothers who are able to regulate their emotions are better equipped to deal with stressors that arise in the context of parenting, thereby enabling them to engage in more supportive response behaviours (see Crandall et al., 2015 for review). In contrast, when parents experience emotions as overwhelming, their arousal is thought to undermine effective parenting and impair parent-child interactions (Dix, 1991). For example, mothers who displayed increased amygdala activation in response to their infant's crying displayed lower levels of maternal sensitivity (Firk et al., 2018). Similarly, difficulties regulating stress (Nyström-Hansen et al., 2019), deficits in emotional face processing (Choi et al., 2017; Thompson-Booth et al., 2014), and structural and functional alterations in brain regions associated with mentalizing and emotional empathy (Mielke et al., 2016; Neukel et al., 2018), have been associated with less sensitive parenting behaviours amongst mothers with a history of child maltreatment.

With respect to more specific parenting behaviours, McCullough and colleagues (2014) found that mothers who scored higher on psychological control, hostility, and unavailability, reported higher levels of child maltreatment than parents belonging to the at-risk or positive parenting groups. Moreover, mothers in the negative parenting group were characterized by lower levels of ER and higher levels of anger compared to the other two groups. Parallel findings were produced by Harel and Finzi-Dottan (2018), who found that retrospective reports of child maltreatment were associated with lower levels of ER, which in turn, predicted more negative parenting practices. Taken together, the relationship between child maltreatment and parenting may be explained by maternal ER difficulties. As such, there is a need to identify other risk factors that could exacerbate parents' emotion dysregulation.

Teenage motherhood and demographic risk factors. Given the relationships between child maltreatment, ER, and parenting, it is important to consider the additional risks conferred by teenage motherhood. A history of child maltreatment has been consistently linked to teenage motherhood (Bert et al., 2009; Garwood et al., 2015; Hillis et al., 2004; Trickett et al., 2011), which in turn, has been associated with demographic risk factors (e.g., single parenthood, lower educational attainment, family poverty) that predict problematic parenting and adverse outcomes in children (see Letourneau et al., 2013 and Serbin \& Karp, 2004 for reviews).

In addition to heightened socioeconomic risk, teenage motherhood has also been associated with postpartum depression and anxiety (Madigan et al., 2014), psychological distress (Mollborn \& Morningstar, 2009), and parenting stress (Spencer et al., 2002). The finding that teen mothers experience more difficulties in these domains is not surprising, since the period of adolescence is already characterized by increases in negative emotionality (Larson et al., 2002), elevated rates of psychopathology (Ahmed, et al., 2015), and the reorganization of the neurocircuitry involved in ER (Casey et al., 2011; Steinberg, 2005). Further, given that brain regions responsible for cognitive control develop more slowly than those that drive emotional reactivity, adolescents may experience more difficulty regulating their emotions in the presence of salient emotional cues (Casey et al., 2011). These findings suggest that maltreated 
women who become teenage mothers may experience more environmental and developmental stressors that make it challenging to regulate their emotions, which in turn, could compromise their ability to engage in sensitive parenting.

In support of this notion, McCullough and colleagues (2015) found that mothers who reported a history of emotional maltreatment in childhood were at an increased risk for engaging in unsupportive parenting behaviours, particularly when they were younger at childbirth (i.e., average age of childbirth $=17.5$ ) and had moderate to high levels of emotion dysregulation. However, given that their assessment was limited to parental psychological control, hostility, and unavailability, more research is needed to investigate other dimensions of unsupportive parenting that may have a more proximal influence on children's emotional development.

\section{Emotion socialization - An understudied parenting behaviour in maltreatment survivors}

Despite a substantial body of literature demonstrating the associations between child maltreatment, ER, and parenting difficulties, parental emotion socialization (ES) practices have been understudied in survivors of child maltreatment. Theoretical models of ES propose that the way parents model, engage with, and react to emotions, as well as the emotional climate of the family, has a profound impact on children's emotional development (Eisenberg et al., 1998; Morris et al., 2007). Unsupportive ES practices, such as punitive or minimizing responses to children's negative emotions, are thought to communicate to children that their negative feelings are unacceptable and should be suppressed (Eisenberg et al., 1998; Gottman et al., 1996; O'Neal \& Magai, 2005). Conversely, supportive responses, such as comforting or problem-solving behaviours, are thought to reduce children's distress and scaffold the acquisition of adaptive ER skills (Eisenberg et al., 1998; Fabes et al., 2002).

Accordingly, parents' unsupportive responses have been associated with negative outcomes in children including maladaptive coping strategies (Sanders et al., 2015), lower levels of socio-emotional competence and ER abilities (Jones et al., 2002; Williams \& Woodruff-Borden, 2015), and higher levels of negative emotional intensity and lability (Fabes et al., 2001; Shaffer et al., 2012). Unsupportive responses have also been linked to behavioural problems and psychopathology in children (Eisenberg et al., 2001; Sanders et al., 2015; Suveg et al., 2008) and adolescents (Katz et al., 2014; O’Neal \& Magai, 2005; Shortt et al., 2016; Stocker et al., 2007). In contrast, supportive parental responses have been associated with better ER skills and constructive coping in children (Cole et al., 2009; Hurrell et al., 2015; Valiente et al., 2004) and adolescents (Criss et al., 2016), as well as lower levels of internalizing difficulties (Briscoe et al., 2019; Hastings et al., 2014). Thus, parents' responses to children's emotions have a strong influence on the trajectory of their emotional development.

Existing literature on child maltreatment and parental emotion socialization. Of the few studies that have focused on child maltreatment and parental ES, the majority have been conducted in samples of maltreating mothers. For example, when compared to a control group, physically maltreating mothers were less likely to engage in discussions that facilitated their child's emotional understanding (Shipman \& Zeman, 1999), less likely to encourage their children to use constructive coping strategies (Shipman \& Zeman, 2001), and more likely to invalidate their children's negative emotions (Shipman et al., 2007). The experience of insufficient ES is also common to neglected children (Shipman et al., 2005) and survivors of sexual abuse (Shipman et al. 2000; Thomas et al., 2011), which suggests that maltreating parents may be less likely to model or teach their children adaptive ER skills.

The tendency to focus on mothers who perpetuate the cycle of child maltreatment is problematic given that the majority of parents who have been maltreated do not go on to abuse or neglect their own children (Schelbe \& Geiger, 2017). Consequently, it is important to attend to the intergenerational transmission of maladaptive parenting more broadly by studying the determinants of parenting behaviours, or factors associated with the persistence of maladaptive parenting across generations (Belsky, 1984; McCloskey, 2017; McCullough et al., 2015). In line with this proposition, some researchers have focused on contextual determinants of parental ES. For instance, Valiente and colleagues (2007) found that higher levels of family chaos predicted less supportive reactions in response to children's negative emotions. Similarly, the relationship between familial risk (i.e., single parenthood, large household size, lower levels of maternal education, low income, and maternal psychological distress) and children's emotional functioning was mediated by mothers' use of unsupportive contingencies (Shaffer et al., 2012).

With respect to individual-level factors, Liu and colleagues (2019) found that a maternal history of emotional abuse predicted higher maternal negative expressivity when children were 14 months old, even when controlling for socio-economic status and maternal histories of physical and sexual abuse. However, given that this study was conducted in China, the impact of childhood physical abuse on maternal ES may have been under-estimated since corporal punishment is still culturally accepted (Liu et al., 2019). In support of this notion, a study of American mothers 
demonstrated that all subtypes of maltreatment were correlated with lower levels of supportive responses to children's negative emotions (Rea \& Shaffer, 2016). Specifically, mothers who reported higher levels of child maltreatment reported that they were less likely to encourage their child to express their emotions and endorsed less emotionfocused reactions (e.g., comforting the child) and problem-focused reactions (e.g., helping the child to solve the problem that was contributing to their distress). Contrary to their expectations, Rea and Shaffer (2016) found no evidence that child maltreatment increased mothers' reports of unsupportive responses such as punitive, minimizing, or distress reactions. The authors hypothesized that it may be easier for mothers to break the cycle of unsupportive behaviours than it is for them to learn a new repertoire of supportive responses, however more research is needed to determine whether these findings can be reproduced.

\section{Connections between parental emotion regulation and emotion socialization practices}

In addition to replicating existing findings, it is crucial to consider mechanisms that might explain the relationship between parents' child maltreatment history and ES practices. Similar to research that has demonstrated the importance of ER to adaptive parenting more broadly (Crandall et al., 2015), ER is thought to play an important role in a parent's ability to provide adaptive ES. Morris and colleagues (2007) hypothesized that parental characteristics such as parents' emotional reactivity, psychopathology, and ER skills - may have indirect effects on children's emotional functioning through their impact on parental ES. Hence, parents who perceive negative emotions as aversive, or who lack the ability to tolerate and manage their own emotions, may become overwhelmed with the emotional demands of parenting and be more likely to engage in self-focused strategies aimed at reducing their own negative affect at the expense of their child's emotional needs (Gottman et al., 1996; Lagacé-Séguin \& Coplan, 2005). Accordingly, parents who reported higher levels of distress when their children expressed negative emotions reported more unsupportive responses, which in turn, was associated with higher emotional intensity and lower social competence in their children (Fabes et al., 2001; 2002). Further, by establishing a relationship between parental psychopathology and unsupportive ES (Arellano et al., 2018; Breaux et al., 2016), researchers have implied that ER difficulties may be a key mechanism underlying this association.

Several studies have identified a link between parents' emotion dysregulation and unsupportive responses including punishing, ignoring, or minimizing the emotions of school-aged (Han et al., 2015; Morelen et al., 2016) and adolescent (Buckholdt et al., 2014; Jones et al., 2014) children. Similarly, parents who reported suppressing their negative emotions were less responsive during parent-child interactions (Le \& Impett, 2016), less likely to report facilitating the expression of their children's negative emotions (Meyer et al., 2014), and more likely to report using unsupportive responses (Hughes \& Gullone, 2010).

In line with the hypothesis proposed by Morris and colleagues (2007), the relationship between maternal ER difficulties and ER difficulties in offspring appears to be mediated by mothers' unsupportive ES (Briscoe et al., 2019; Buckholdt et al., 2014; Morelen et al., 2016). However, just as deficits in parental ER may contribute to unsupportive responses, it is also true that the presence of adaptive ER may prevent parents from engaging in unsupportive behaviours. For instance, parents who exhibited more adaptive ER during parent-child interactions (Morelen et al., 2016) and reported higher levels of emotional awareness, acceptance, and clarity (Meyer et al., 2014; Yap et al., 2008) were less likely to report using unsupportive responses with preschool (Meyer et al., 2014), school-aged (Morelen et al., 2016), and adolescent (Yap et al., 2008) children. Moreover, a parents' ability to reappraise upsetting situations may facilitate the use of supportive responses when children are in distress (Cabecinha-Alati, Malikin, \& Montreuil, in press; Hughes \& Gullone, 2010; Meyer et al., 2014). Consequently, parents who are more capable of regulating their emotions may be better equipped to respond to children in supportive ways, whereas those who struggle with ER may utilize unsupportive responses.

Studies in survivors of child maltreatment. Although there is a dearth of literature that examines parental ER and ES in child maltreatment survivors, there is some evidence to suggest that a history of child maltreatment, and subsequent ER difficulties, have an effect on parental ES. For example, researchers have postulated that mothers with borderline personality disorder (BPD) - and presumably a history of emotional abuse (Linehan, 1993) - may lack the ability to understand and manage their emotions, which in turn, could make them less likely to engage in adaptive ES (Stepp et al., 2012). This hypothesis was corroborated in a study that showed that the relationship between maternal BPD symptoms and unsupportive ES was mediated by maternal ER difficulties (Kiel et al., 2017). However, given that child maltreatment history was not assessed, this study only offers tentative support. 
To our knowledge, only two studies have examined the relationships between child maltreatment, parental ER, and ES. Cabecinha-Alati, Langevin and colleagues (2020) found that higher levels of childhood polyvictimization predicted lower levels of parental ER skills, which in turn, predicted parents' use of unsupportive responses when their children expressed negative emotions. However, they did not assess adult experiences of revictimization. In contrast, Martin and colleagues (2018) found that mothers who experienced high betrayal trauma revictimization (i.e., high betrayal trauma in both childhood and adulthood) were more likely to report distress reactions in response to their adolescents' expressions of negative affect. Additionally, the relationship between mothers' victimization and negative responsivity was mediated by maternal ER difficulties such that mothers who experienced revictimization experienced higher levels of emotion dysregulation, which in turn, was positively associated with their negative responsivity (Martin et al., 2018). These findings coincide with studies that emphasize the detrimental role of child maltreatment and revictimization on parenting (Banyard et al., 2003; Cole et al., 2009; Dubowitz et al., 2001), as well as studies that have established links between revictimization and heightened levels of emotion dysregulation (Walsh et al., 2011), and emotion dysregulation and unsupportive ES (e.g., Buckholdt et al., 2014; Morelen et al., 2016). However, more research is needed to corroborate these findings in parents with a history of child maltreatment.

\section{Conceptual model of the intergenerational transmission of emotion dysregulation}

Building upon the literature reviewed, the ensuing section describes a novel conceptual model that elucidates some of the mechanisms involved in the intergenerational transmission of emotion dysregulation. Although the relationships between child maltreatment and adult ER difficulties (e.g., Burns et al., 2010), parental ER and ES (e.g., Morelen et al., 2016), and parental ES and offspring ER (e.g., Shortt et al., 2016), have been supported in studies that examined these constructs separately, it appears that only two studies (Cabecinha-Alati, Langevin et al., 2020; Martin et al., 2018) have tested these relationships simultaneously. Furthermore, there is currently no comprehensive model that accounts for the associations between these constructs.

Given that the majority of the research outlined in this review has been conducted in samples composed of women, the model will be applicable to mothers who endorse a history of child maltreatment. The framework for the model was informed by pre-existing models including The Resource Loss Model of Childhood Abuse Trauma (Cloitre, Cohen, \& Koenen, 2011) theories pertaining to betrayal trauma and complex trauma (Freyd, 1996; van der Kolk, 1996; 2005), The Affective Organization of Parenting Model (Dix, 1991), and theoretical models of parental ES (Eisenberg et al., 1998; Morris et al., 2007) and social learning (Bandura, 1977).

It is hypothesized that a maternal history of child maltreatment will have both direct and indirect effects on parental ES practices through the various mechanisms illustrated below (see Figure 1). Moreover, maternal ES practices are expected to influence the ER difficulties of offspring in the next generation.

\section{Indirect effects of child maltreatment history on parental emotion socialization}

In this model, the indirect relationship between child maltreatment and parental ES in adulthood is thought to be attributable to the negative sequelae of child maltreatment. More specifically, child maltreatment has been associated with changes in the neurobiological systems underlying ER (e.g., Caldwell et al., 2014; Dannlowski et al., 2012) and ER difficulties that persist into adulthood (e.g., Burns et al., 2010; Ehring \& Quack, 2010), presumably because child maltreatment contributes to disruptions in attachment relationships with primary caregivers that interfere with the development of affect regulation (Cloitre, Cohen, \& Koenen, 2011; Schore \& Schore, 2008). Child maltreatment has also been shown to increase the risk of teenage motherhood (Garwood et al., 2015; Hillis et al., 2004) and revictimization in the context of adult relationships (Arias, 2004; Desai et al., 2002). Given the association between teenage motherhood, post-partum psychopathology, and parenting stress (Madigan et al., 2014; Spencer et al., 2000), as well as the protracted cognitive development that occurs during adolescence (Casey et al., 2011), teen mothers may experience higher levels of ER difficulties which in turn, negatively impact parenting (McCullough et al., 2015). The experience of additional traumas in adulthood also contributes to parenting problems (Banyard et al., 2003; Cole et al., 2009), likely because experiences of revictimization can exacerbate ER difficulties (Martin et al., 2018; Walsh et al., 2011), which increases the risk of further revictimization (Messman-Moore et al., 2010). 

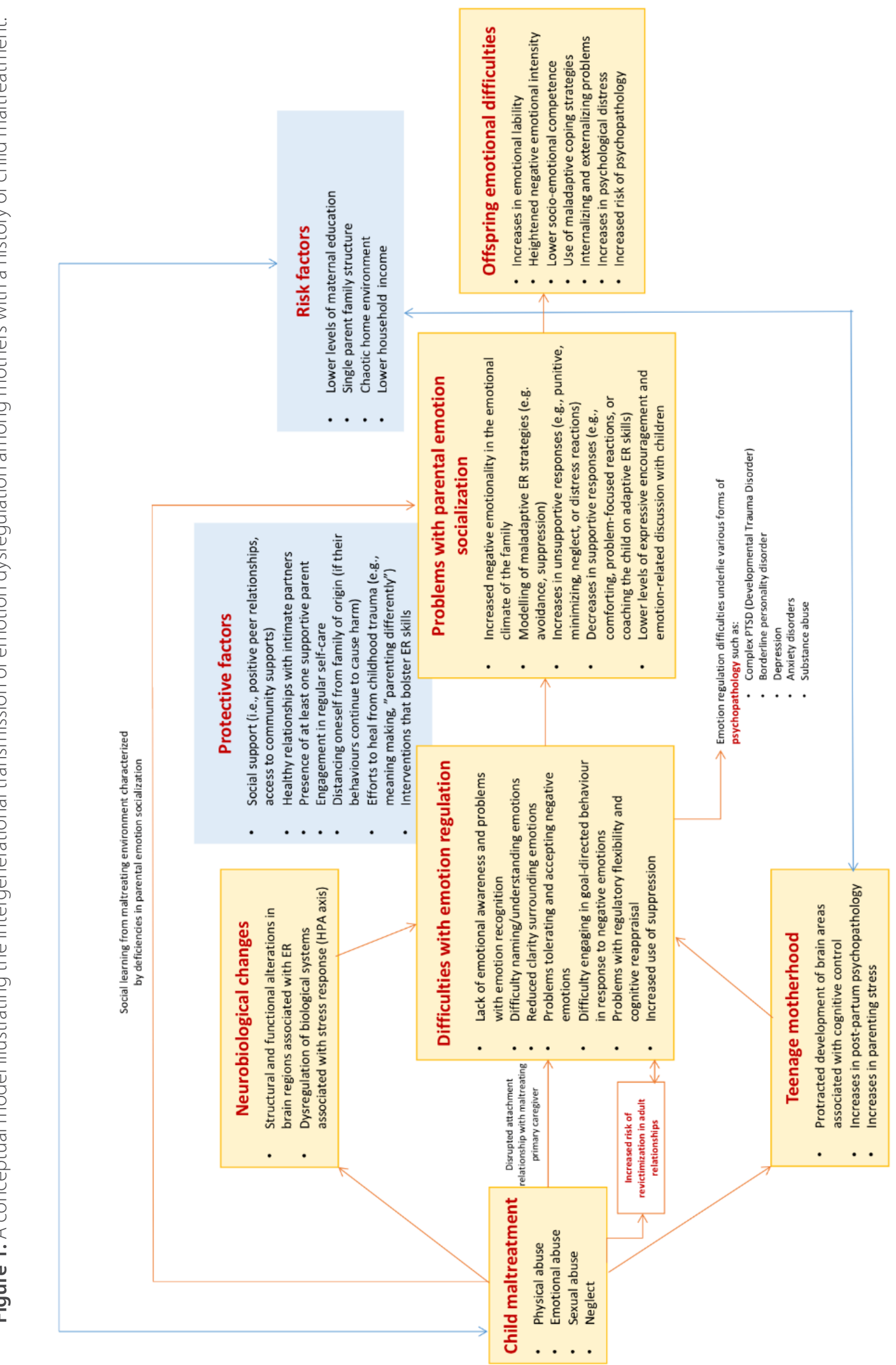
Subsequently, ER difficulties interfere with adaptive parenting as evidenced by studies that have documented a relationship between parental emotion dysregulation and unsupportive ES practices (e.g., Briscoe et al., 2019; Han et al., 2015; Morelen et al., 2016). With regard to child maltreatment survivors, caregivers who have experienced this complex trauma may be even more likely to avoid negative emotions, which in turn, would impair their ability to respond supportively when children experience distress (Cook et al., 2005; Zvara, Mills-Koonce \& Cox, 2017). Preliminary evidence suggests that parental ER difficulties play a role in the relationship between childhood maltreatment and problems with parental ES including higher levels of maternal negative expressivity (Liu et al., 2019), lower levels of supportive responses (Rea \& Shaffer, 2016), and higher levels of negative responsivity (Martin et al., 2018). In turn, deficiencies in parental ES are likely to contribute to emotional problems in offspring (e.g., Sanders et al., 2015; Shaffer et al., 2012).

To summarize, the conceptual model proposes that experiences of child maltreatment have detrimental impacts on ER that persist into adulthood and increase the likelihood of other risk factors (e.g., teenage motherhood and revictimization) that can have an adverse effect on ER. In turn, ER difficulties are thought to interfere with the parental role and put children at risk for emotional difficulties by compromising various dimensions of ES including the emotional climate of the family, parents' ability to model adaptive ER strategies, parents' contingent responses to their child's negative emotions, and the ability to engage in emotional discussions with children. Protective factors such as social support, secure attachment with a supportive caregiver, healthy relationships with peers and intimate partners in adulthood, engagement in regular self-care, and other efforts to heal from childhood trauma can mitigate the effects of child maltreatment on ER and parenting (Alink et al., 2009; Chamberlain et al., 2019; Collishaw et al., 2007; DuMont et al., 2007; Kooiman et al., 2004). Conversely, familial and environmental risk factors (e.g., single parenthood, lower levels of maternal education, and an impoverished or chaotic home environment) can exacerbate difficulties with parental ES (Shaffer et al., 2012; Valiente et al., 2007) and contribute to poor developmental outcomes in children (Letourneau et al., 2013; Serbin \& Karp, 2004).

\section{Direct effects of child maltreatment history on parental emotion socialization}

In addition to the indirect effects of child maltreatment on parents' ES through parental ER, child maltreatment may also have direct effects on parental ES as a result of social learning (Bandura, 1977). Numerous studies suggest that maltreating parents fail to act as effective ES agents for their children (e.g., Shipman et al., 2005; 2007; Shipman \& Zeman, 2001). Consequently, children who grow up in maltreating environments are less likely to be exposed to parents who model adaptive ES practices and are more likely to be exposed to parents who model abusive or emotionally invalidating behaviours, which in turn, could make them more likely to engage in unsupportive parenting with their own children (Baker \& Crnic, 2005; Conger et al., 2003; McCullough et al., 2015). Martin and colleagues (2018) found that the direct path from maternal high betrayal trauma revictimization to mothers' negative responsivity became nonsignificant when maternal ER difficulties were added to the model. However, given that they only assessed maternal distress responses, these findings should not be generalized to other dimensions of unsupportive ES (such as punitive responses), that may be more susceptible to replication through social learning. Therefore, more research is needed to ascertain the effects of child maltreatment on these aspects of parental ES.

\section{Directions for future research}

Given the importance of ER for parenting and children's wellbeing, there is a strong need to elucidate the mechanisms by which parental emotion dysregulation is transmitted to children (Rutherford et al., 2015) and to understand the role of parents' child maltreatment history and parental ES in this relationship. The conceptual model presented can guide future research by informing the development of mediation or moderation models that test for direct and indirect effects of child maltreatment on parental ES. Once these relationships are established in mothers, future research should focus on fathers, who are underrepresented in the literature (e.g., Wark \& Vis, 2018). Additionally, since the majority of studies examining parental ES have focused on parents of preschool or school-aged children, the literature examining parental ES in adolescence is relatively sparse (Zeman et al., 2013), necessitating more research in this area. Finally, given that most studies on child maltreatment and parenting have focused predominantly on physical and sexual abuse (see Vaillancourt et al., 2017), more research is needed to investigate the impact of exposure to intimate partner violence (IPV), neglect, and emotional maltreatment since these are amongst the most common forms of child maltreatment being reported (Chamberland et al., 2011; Fallon et al., 2020; Maguire \& Naughton, 2016). Despite increasing recognition of the detrimental effects of exposure to IPV in childhood (e.g., Roustit et al., 2009), this subtype of maltreatment was not included in the present review because it is not perpetrated against the child per se. 


\section{Limitations}

Despite the utility of the conceptual model, there are several limitations that warrant consideration. Firstly, it is important to recognize that culture (Dunsmore \& Halberstadt, 2009; Friedlmeier et al., 2011) and gender (Cassano \& Zeman, 2010; Zeman et al., 2010) may be strong determinants of parental ES and its effects on children's ER. However, these variables were not included in the present model. Moreover, although many relationships are portrayed as unidirectional, there are undoubtedly reciprocal influences that should be considered. For example, child characteristics such as personality, temperament, and emotional reactivity (Mazzone \& Nader-Grosbois, 2017; Morris et al., 2007; Yap et al., 2008) as well as the child's ER abilities (Morelen \& Suveg, 2012) have an influence on parents' ES practices. There is also evidence to suggest that moderating factors, such as children's level of physiological reactivity (McQuade \& Breaux, 2017) and support-seeking behaviours (Miller-Slough et al., 2016), might influence the extent to which parents' unsupportive responses impact children's ER. Although unsupportive ES has been related to poor ER and behavioural problems in children, high levels of emotion coaching when children expressed negative emotions was found to buffer against the detrimental effects of parents' dismissing responses (Lunkenheimer et al., 2007). Thus, it is also important to consider protective factors that could prevent the development ER difficulties in children who are exposed to unsupportive ES.

Another limitation is that this model pertains to the transmission of emotion dysregulation amongst mothers with a history of child maltreatment. More research is beginning to examine the unique influence of fathers in the process of ES (e.g., Gerhardt et al., 2020) and despite widespread recognition that ES occurs within the family system (Morris et al., 2007), there is a paucity of literature on how mothers and fathers socialize children's development in an interactive way (Poon et al., 2017). A study by McElwain and colleagues (2007) found that when one parent reported low levels of supportive ES, greater support by the other parent was related to higher levels of emotional understanding in children. However, when one parent reported high levels of supportive ES, high levels of support from the other parent was actually associated with less optimal functioning. As such, rather than supporting an additive model wherein higher levels of support yield better outcomes, a growing body of evidence supports a divergence model in which children's psychosocial adjustment is facilitated by exposure to a diverse range of parental responses characterized by varying levels of maternal and paternal supportiveness (Miller et al., 2015; Miller-Slough et al., 2018; Poon et al., 2017).

In addition to studies examining interactive effects of ES, some research has examined cross-over effects between spouses. For example, Bai and Han (2016) found that childhood emotional abuse experienced by one parent was positively associated with parenting stress in the other parent and determined that this relationship was mediated by the abused parent's emotional dysregulation. Similarly, Li and colleagues (2019) showed that higher levels of maternal emotion dysregulation predicted lower levels of supportive ES from fathers and indicated that this relationship was mediated by father's reports of marital conflict. It remains unclear how interactions within the family system might moderate the impact of maternal unsupportive ES on children's emotional development and as such, this might be an area for future research.

Lastly, although the majority of ES research has been conducted within the family context (Miller-Slough \& Dunsmore, 2016), extra-familial influences not included in the model could also influence the trajectory of children's emotional development. For example, childhood teachers act as ES agents for their students by modelling emotions, engaging in instruction regarding children's emotional experiences, and their contingent responding to children's emotional expressions (Morris et al., 2013). As children transition into adolescence, it becomes even more crucial to consider how extra-familial socialization by peers, romantic partners, and the media can influence ER (Brand \& KlimesDougan, 2010). Some studies have examined the influence of peer ES (Borowski et al., 2018; Klimes-Dougan et al., 2014), however studies examining the role of parent and friend ES tend to do so concurrently, rather than examining interactive effects (Cui et al., 2020; Miller-Slough \& Dunsmore, 2019). As such, the combined influence of multiple socializers remains equivocal and more research is needed to determine whether supportive ES from extra-familial sources might mitigate the negative impact of parents' unsupportive ES on children's emotional development. 


\section{Clinical implications}

Notwithstanding these limitations, this review and conceptual model have important clinical implications. To attenuate the consequences of child maltreatment and promote resilience in future generations, it is crucial to provide increased access to services designed for parents who were maltreated as children (Plant et al., 2018). In line with the conceptual model, such services should focus on ameliorating parental ER difficulties. Ford and colleagues (2005) reviewed several interventions for complex trauma and one of the most important common factors was an initial phase that focused on developing the client's self-regulation skills. Similarly, best practices for the treatment of complex PTSD suggest that first-line interventions should specifically target ER difficulties (Cloitre, Courtois et al., 2011). Given that parents must be able to tolerate their own distress in order to engage in adaptive, child-focused parenting practices (Gottman et al., 1996; Lagacé-Séguin \& Coplan, 2005), bolstering parental ER skills may be a first step to disrupting the intergenerational transmission of emotion dysregulation and promoting resilience in children.

Despite the pervasiveness of child maltreatment and the need to improve ER in this vulnerable population, the majority of those who have been maltreated do not utilize outpatient mental health services (Ringeisen et al., 2009). As such, parenting programs that target at-risk populations may be a more effective and accessible option. In a metaanalysis investigating the effectiveness of parenting programs, those that provided training in emotional communication reported significantly larger positive differences in parenting behaviours than those that did not (Kaminski et al., 2008). In line with the shift towards recognizing transdiagnostic mechanisms involved in psychopathology (Aldao et al., 2010; Gross \& Jazaieri, 2014), there has also been increased emphasis on transdiagnostic programs that target parental ER skills (Maliken \& Katz, 2013). The Tuning into Kids and Tuning into Teens programs in Australia (Havighurst \& Harley, 2007a; 2007b) have been successful in improving parental ER abilities, decreasing parents' use of unsupportive ES practices, and increasing supportive ES (Havighurst et al., 2010; 2013; 2015; Kehoe et al., 2014). These parenting programs have also yielded positive outcomes amongst children including improvements in emotional knowledge and reductions in externalizing and internalizing difficulties (Havighurst et al., 2010; 2013; 2015; Kehoe et al., 2014). Similar programs could be developed for parents with a history of child maltreatment in Canada, however it would be important to take a trauma-informed approach that acknowledges the ambivalence around helpseeking and facilitates sessions in a child-friendly, non-clinical setting that fosters social support, optimism, and healing (Muzik, Ads, et al., 2013).

\section{Conclusion}

The review and conceptual model presented provide a theoretical and empirical synthesis of research examining child maltreatment, ER, and parenting behaviours, with an emphasis on parental ES. More research is needed to validate the conceptual model and to support the development of trauma-informed parenting programs that disrupt the transmission of emotion dysregulation and promote resilience in future generations.

\section{Funding}

Sarah Cabecinha-Alati currently holds a Joseph-Armand Bombardier Scholarship. This research was also supported by a McGill Social Sciences and Humanities Grant awarded to Tina Montreuil.

\section{Conflict of interest}

The authors have no conflict of interest to disclose.

\section{References}

Ahmed, S. P., Bittencourt-Hewitt, A., \& Sebastian, C. L. (2015). Neurocognitive bases of emotion regulation development in adolescence. Developmental Cognitive Neuroscience, 15, 11-25. https://doi.org/10.1016/j.dcn.2015.07.006

Ainsworth, M. D. S. (1969). Object relations, dependency, and attachment: A theoretical review of the infant-mother relationship. Child Development, 40(4), 969-1025. https://doi.org/10.2307/1127008

Aldao, A., Nolen-Hoeksema, S., \& Schweizer, S. (2010). Emotion-regulation strategies across psychopathology: A meta-analytic review. Clinical Psychology Review, 30(2), 217-237. https://doi.org/10.1016/j.cpr.2009.11.004 
Alink, L. R., Cicchetti, D., Kim, J., \& Rogosch, F. A. (2009). Mediating and moderating processes in the relation between maltreatment and psychopathology: Mother-child relationship quality and emotion regulation. Journal of Abnormal Child Psychology, 376), 831-843. https://doi.org/10.1007/s10802-009-9314-4

Ardizzi, M., Martini, F., Umiltà, M. A., Evangelista, V., Ravera, R., \& Gallese, V. (2015). Impact of childhood maltreatment on the recognition of facial expressions of emotions. PLOS One, 1010), Article e0141732. https://doi.org/10.1371/journal.pone.0141732

Arellano, B., Gramszlo, C., \& Woodruff-Borden, J. (2018). Parental reactions to children's negative affect: The moderating role of parental GAD. Journal of Anxiety Disorders, 53, 22-29. https://doi.org/10.1016/j.janxdis.2017.10.006

Arias, I. (2004). Report from the CDC. The legacy of child maltreatment: Long-term health consequences for women. Journal of Women's Health, 13(5), 468-473. https://doi.org/10.1089/1540999041280990

Bai, L., \& Han, Z. R. (2016). Emotion dysregulation mediates relations between Chinese parents' histories of childhood emotional abuse and parenting stress: A dyadic data analysis. Parenting: Science and Practice, 16(3), $187-205$. https://doi.org/10.1080/15295192.2016.1158602

Bailey, H. N., DeOliveira, C. A., Wolfe, V. V., Evans, E. M., \& Hartwick, C. (2012). The impact of childhood maltreatment history on parenting: A comparison of maltreatment types and assessment methods. Child Abuse \& Neglect, 36(3), $236-246$. https://doi.org/10.1016/j.chiabu.2011.11.005

Baker, J. K., \& Crnic, K. A. (2005). The relation between mothers' reports of family-of-origin expressiveness and their emotion-related parenting. Parenting: Science and Practice, 5(4), 333-346. https://doi.org/10.1207/s15327922par0504_2

Bandura, A. (1977). Social learning theory (Vol. 1). Prentice Hall.

Banyard, V. L., Williams, L. M., \& Siegel, J. A. (2003). The impact of complex trauma and depression on parenting: An exploration of mediating risk and protective factors. Child Maltreatment, 8(4), 334-349. https://doi.org/10.1177/1077559503257106

Barlow, M. R., Turow, R. E. G., \& Gerhart, J. (2017). Trauma appraisals, emotion regulation difficulties, and self-compassion predict posttraumatic stress symptoms following childhood abuse. Child Abuse \& Neglect, 65, 37-47. https://doi.org/10.1016/j.chiabu.2017.01.006

Beeghly, M., Olson, K. L., Weinberg, M. K., Pierre, S. C., Downey, N., \& Tronick, E. Z. (2003). Prevalence, stability, and socio-demographic correlates of depressive symptoms in Black mothers during the first 18 months postpartum. Maternal and Child Health Journal, 73), 157-168. https://doi.org/10.1023/A:1025132320321

Belsky, J. (1984). The determinants of parenting: A process model. Child Development, 55(1), 83-96. https://doi.org/10.2307/1129836

Bert, S. C., Guner, B. M., Lanzi, R. G., \& the members of Centers for Prevention of Child Neglect. (2009). The influence of maternal history of abuse on parenting knowledge and behavior. Family Relations, 58(2), $176-187$. https://doi.org/10.1111/j.1741-3729.2008.00545.x

Borowski, S. K., Zeman, J., \& Braunstein, K. (2018). Social anxiety and socioemotional functioning during early adolescence: The mediating role of best friend emotion socialization. Journal of Early Adolescence, 38(2), 238-260. https://doi.org/10.1177/0272431616665212

Bowlby, J., (1969). Attachment and loss (Vol. 1: Attachment). Basic Books.

Brand, A. E., \& Klimes-Dougan, B. (2010). Emotion socialization in adolescence: The roles of mothers and fathers. New Directions for Child and Adolescent Development, 2010(128), 85-100. https://doi.org/10.1002/cd.270

Breaux, R. P., Harvey, E. A., \& Lugo-Candelas, C. I. (2016). The role of parent psychopathology in emotion socialization. Journal of Abnormal Child Psychology, 44(4), 731-743. https://doi.org/10.1007/s10802-015-0062-3

Briere, J., \& Rickards, S. (2007). Self-awareness, affect regulation, and relatedness: Differential sequels of childhood versus adult victimization experiences. Journal of Nervous and Mental Disease, 195(6), $497-503$. https://doi.org/10.1097/NMD.0b013e31803044e2

Briscoe, C., Stack, D. M., Dickson, D. J., \& Serbin, L. A. (2019). Maternal emotion socialization mediates the relationship between maternal and adolescent negative emotionality. Journal of Youth and Adolescence, 48(3), 495-509. https://doi.org/10.1007/s10964-018-0945-z

Buckholdt, K. E., Parra, G. R., \& Jobe-Shields, L. (2014). Intergenerational transmission of emotion dysregulation through parental invalidation of emotions: Implications for adolescent internalizing and externalizing behaviors. Journal of Child and Family Studies, 23(2), 324-332. https://doi.org/10.1007/s10826-013-9768-4

Buist, A., Gotman, N., \& Yonkers, K. A. (2011). Generalized anxiety disorder: Course and risk factors in pregnancy. Journal of Affective Disorders, 131(1-3), 277-283. https://doi.org/10.1016/j.jad.2011.01.003 
Burczycka, M. (2017). Section 1: Profile of Canadian adults who experienced childhood maltreatment. In Family violence in Canada: A statistical profile, 2015. Juristat: Canadian Centre for Justice Statistics. https://www150.statcan.gc.ca/n1/en/pub/85-002-x/2017001/article/14698-eng.pdf?st=NO2L1tvx

Burns, E. E., Jackson, J. L., \& Harding, H. G. (2010). Child maltreatment, emotion regulation, and posttraumatic stress: The impact of emotional abuse. Journal of Aggression, Maltreatment \& Trauma, 19(8), 801-819. https://doi.org/10.1080/10926771.2010.522947

Cabecinha-Alati, S., Langevin, R., Kern, A., \& Montreuil, T. C. (2020). Pathways from childhood maltreatment to unsupportive emotion socialization: implications for children's emotional inhibition. Journal of Family Violence. Advance online publication. https://doi.org/10.1007/s10896-020-00184-y

Cabecinha-Alati, S., Malikin, H., \& Montreuil, T.C. (in press). Emotion regulation and personality as predictors of mothers' emotion socialization practices. Family Relations.

Caldwell, J. G., Krug, M. K., Carter, C. S., \& Minzenberg, M. J. (2014). Cognitive control in the face of fear: Reduced cognitive-emotional flexibility in women with a history of child abuse. Journal of Aggression, Maltreatment \& Trauma, 23(5), 454-472. https://doi.org/10.1080/10926771.2014.904466

Caldwell, J. G., Shaver, P. R., Li, C. S., \& Minzenberg, M. J. (2011). Effects of childhood maltreatment: Childhood maltreatment, adult attachment, and depression as predictors of parental self-efficacy in at-risk mothers. Journal of Aggression, Maltreatment and Trauma, 2066), 595-616. https://doi.org/10.1080/10926771.2011.595763

Casey, B. J., Jones, R. M., \& Somerville, L. H. (2011). Braking and accelerating of the adolescent brain. Journal of Research on Adolescence, 21(1), 21-33. https://doi.org/10.1111/j.1532-7795.2010.00712.x

Cassano, M. C., \& Zeman, J. L. (2010). Parental socialization of sadness regulation in middle childhood: The role of expectations and gender. Developmental Psychology, 46(5), 1214-1226. https://doi.org/10.1037/a0019851

Chamberland, C., Fallon, B., Black, T., \& Trocmé, N. (2011). Emotional maltreatment in Canada: Prevalence, reporting and child welfare responses (CIS2). Child Abuse \& Neglect, 35(10), 841-854. https://doi.org/10.1016/j.chiabu.2011.03.010

Chamberlain, C., Gee, G., Harfield, S., Campbell, S., Brennan, S., Clark, Y., Mensah, F., Arabena K., Herrman, H., Brown, S., \& the 'Healing the Past by Nurturing the Future' group. (2019). Parenting after a history of childhood maltreatment: A scoping review and map of evidence in the perinatal period. PLOS ONE, 14(3). https://doi.org/10.1371/journal.pone.0213460

Choi, K. W., Sikkema, K. J., Vythilingum, B., Geerts, L., Faure, S. C., Watt, M. H., Roos, A., \& Stein, D. J. (2017). Maternal childhood trauma, postpartum depression, and infant outcomes: Avoidant affective processing as a potential mechanism. Journal of Affective Disorders, 211, 107-115. https://doi.org/10.1016/j.jad.2017.01.004

Cicchetti, D., \& Toth, S. L. (2005). Child maltreatment. Annual Review of Clinical Psychology, 1, $409-438$. https://doi.org/10.1146/annurev.clinpsy.1.102803.144029

Cloitre, M., Cohen, L. R., \& Koenen, K. C. (2011). The trauma of childhood abuse: A resource loss model. In M. Cloitre, L. R. Cohen \& K. C. Koenen (Eds.), Treating survivors of childhood abuse: Psychotherapy for the interrupted life (pp. 1-13). Guilford Press.

Cloitre, M., Courtois, C. A., Charuvastra, A., Carapezza, R., Stolbach, B. C., \& Green, B. L. (2011). Treatment of complex PTSD: Results of the ISTSS expert clinician survey on best practices. Journal of Traumatic Stress, 24(6), 615-627. https://doi.org/10.1002/jts.20697

Cloitre, M., Miranda, R., Stovall-McClough, K. C., \& Han, H. (2005). Beyond PTSD: Emotion regulation and interpersonal problems as predictors of functional impairment in survivors of childhood abuse. Behavior Therapy, 36(2), 119-124. https://doi.org/10.1016/S0005-7894(05)80060-7

Cohen, L. R., Hien, D. A., \& Batchelder, S. (2008). The impact of cumulative maternal trauma and diagnosis on parenting behavior. Child Maltreatment, 13(1), 27-38. https://doi.org/10.1177/1077559507310045

Cole, P. M., Dennis, T. A., Smith-Simon, K. E., \& Cohen, L. H. (2009). Preschoolers' emotion regulation strategy understanding: Relations with emotion socialization and child self-regulation. Social Development, 18(2), 324-352. https://doi.org/10.1111/j.14679507.2008.00503.x

Collin-Vezina, D., Cyr, M., Pauze, R., \& McDuff, P. (2005). The role of depression and dissociation in the link between childhood sexual abuse and later parental practices. Journal of Trauma \& Dissociation, 6(1), 71-97. https://doi.org/10.1300/J229v06n01_05

Collishaw, S., Pickles, A., Messer, J., Rutter, M., Shearer, C., \& Maughan, B. (2007). Resilience to adult psychopathology following childhood maltreatment: Evidence from a community sample. Child Abuse \& Neglect, 37(3), $211-229$. https://doi.org/10.1016/j.chiabu.2007.02.004

Conger, R. D., Neppl, T., Kim, K. J., \& Scaramella, L. (2003). Angry and aggressive behavior across three generations: A prospective, longitudinal study of parents and children. Journal of Abnormal Child Psychology, 37(2), 143-160. https://doi.org/10.1023/A:1022570107457 
Cook, A., Spinazzola, J., Ford, J., Lanktree, C., Blaustein, M., Cloitre, M., De Rosa, R., Hubbard, R., Kagan, R., Liautard, J., Mallah, K., Olafson, E., \& van der Kolk, B., (2005). Complex trauma in children and adolescents. Psychiatric Annals, 35(5), $390-398$. https://doi.org/10.3928/00485713-20050501-05

Crandall, A., Deater-Deckard, K., \& Riley, A. W. (2015). Maternal emotion and cognitive control capacities and parenting: A conceptual framework. Developmental Review, 36, 105-126. https://doi.org/10.1016/j.dr.2015.01.004

Criss, M. M., Morris, A. S., Ponce-Garcia, E., Cui, L., \& Silk, J. S. (2016). Pathways to adaptive emotion regulation among adolescents from low-income families. Family Relations, 65(3), 517-529. https://doi.org/10.1111/fare.12202

Crow, T., Cross, D., Powers, A., \& Bradley, B. (2014). Emotion dysregulation as a mediator between childhood emotional abuse and current depression in a low-income African-American sample. Child Abuse \& Neglect, 38(10), $1590-1598$. https://doi.org/10.1016/j.chiabu.2014.05.015

Cui, L., Criss, M. M., Ratliff, E., Wu, Z., Houltberg, B. J., Silk, J. S., \& Morris, A. S. (2020). Longitudinal links between maternal and peer emotion socialization and adolescent girls' socioemotional adjustment. Developmental Psychology, 56(3), 595-607. https://doi.org/10.1037/dev0000861

Dannlowski, U., Kugel, H., Huber, F., Stuhrmann, A., Redlich, R., Grotegerd, D., Dohm, K., Sehlmeyer, C., Konrad, C., Baune, B. T., Arolt, V., Heindel, W., Zwitzerlood, P., \& Suslow, T. (2013). Childhood maltreatment is associated with an automatic negative emotion processing bias in the amygdala. Human Brain Mapping, 34(11), 2899-2909. https://doi.org/10.1002/hbm.22112

Dannlowski, U., Stuhrmann, A., Beutelmann, V., Zwanzger, P., Lenzen, T., Grotegerd, D., Domschke, K., Hohoff, C., Ohrmann, P., Bauer, J., Lindner, C., Postert, C., Konrad, C., Arolt, V., Heindel, W., Suslow, T., \& Kugel, H. (2012). Limbic scars: Long-term consequences of childhood maltreatment revealed by functional and structural magnetic resonance imaging. Biological Psychiatry, 71(4), 286-293. https://doi.org/10.1016/j.biopsych.2011.10.021

Desai, S., Arias, I., Thompson, M. P., \& Basile, K. C. (2002). Childhood victimization and subsequent adult revictimization assessed in a nationally representative sample of women and men. Violence and Victims, 17(6), 639-653. https://doi.org/10.1891/vivi.17.6.639.33725

DiLillo, D., Tremblay, G. C., \& Peterson, L. (2000). Linking childhood sexual abuse and abusive parenting: The mediating role of maternal anger. Child Abuse \& Neglect, 24(6), 767-779. https://doi.org/10.1016/S0145-2134(00)00138-1

Driscoll, J. R., \& Easterbrooks, A. M. (2007). Young mothers' play with their toddlers: Individual variability as a function of psychosocial factors. Infant and Child Development, 16(6), 649-670. https://doi.org/10.1002/icd.515

Dix, T. (1991). The affective organization of parenting: Adaptive and maladaptative processes. Psychological Bulletin, 110(1), 3-25. https://doi.org/10.1037/0033-2909.110.1.3

Dubowitz, H., Black, M. M., Kerr, M. A., Hussey, J. M., Morrel, T. M., Everson, M. D., \& Starr, R. H. (2001). Type and timing of mothers' victimization: Effects on mothers and children. Pediatrics, 1074), 728-735. https://doi.org/10.1542/peds.107.4.728

DuMont, K. A., Widom, C. S., \& Czaja, S. J. (2007). Predictors of resilience in abused and neglected children grown-up: The role of individual and neighborhood characteristics. Child Abuse \& Neglect, 37(3), 255-274. https://doi.org/10.1016/j.chiabu.2005.11.015

Dunsmore, J. C., \& Halberstadt, A. G. (2009). The dynamic cultural context of emotion socialization. In J., Mancini \& K.A., Roberto (Eds.), Pathways of human development: Explorations of change (pp. 171-190). Lexington Books/Rowman \& Littlefield.

Easterbrooks, M. A., Chaudhuri, J. H., Bartlett, J. D., \& Copeman, A. (2011). Resilience in parenting among young mothers: Family and ecological risks and opportunities. Children and Youth Services Review, 33(1), 42-50. https://doi.org/10.1016/j.childyouth.2010.08.010

Ehrensaft, M. K., Knous-Westfall, H. M., Cohen, P., \& Chen, H. (2015). How does child abuse history influence parenting of the next generation? Psychology of Violence, 5(1), 16-25. https://doi.org/10.1037/a0036080

Ehring, T., \& Quack, D. (2010). Emotion regulation difficulties in trauma survivors: The role of trauma type and PTSD symptom severity. Behavior Therapy, 41(4), 587-598. https://doi.org/10.1016/j.beth.2010.04.004

Eisenberg, N., Cumberland, A., \& Spinrad, T. L. (1998). Parental socialization of emotion. Psychological Inquiry, 944), 241-273. https://doi.org/10.1207/s15327965pli0904_1

Eisenberg, N., Losoya, S., Fabes, R. A., Guthrie, I. K., Reiser, M., Murphy, B., Shepard, S. A., Poulin, R., \& Padgett, S. J. (2001). Parental socialization of children's dysregulated expression of emotion and externalizing problems. Journal of Family Psychology, 15(2), 183-205. https://doi.org/10.1037/0893-3200.15.2.183

Eisenberg, N., \& Morris, A. S. (2002). Children's emotion-related regulation. In R. V. Kail (Ed.), Advances in child development and behavior, Vol. 30 (pp. 189-229). Academic Press. https://doi.org/10.1016/S0065-2407(02)80042-8

Elliot, R. L., Campbell, L., Hunter, M., Cooper, G., Melville, J., McCabe, K., Newman, L., \& Loughland, C. (2014). When I look into my baby's eyes... Infant emotion recognition by mothers with borderline personality disorder. Infant Mental Health Journal, $35(1), 21-32$. https://doi.org/10.1002/imhj.21426 
Fabes, R. A., Leonard, S. A., Kupanoff, K., \& Martin, C. L. (2001). Parental coping with children's negative emotions: Relations with children's emotional and social responding. Child Development, 72(3), 907-920. https://doi.org/10.1111/1467-8624.00323

Fabes, R. A., Poulin, R. E., Eisenberg, N., \& Madden-Derdich, D. A. (2002). The Coping with Children's Negative Emotions Scale (CCNES): Psychometric properties and relations with children's emotional competence. Marriage \& Family Review, 34(3-4), $285-310$. https://doi.org/10.1300/J002v34n03_05

Fallon, B., Filippelli, J., Lefebvre, R., Joh-Carnella, N., Trocmé, N., Black, T., MacLaurin, B., Hélie, S., Morin, Y., Fluke, J., King, B., Esposito, T., Collin-Vézina, D., Allan, K., Houston, E., Harlick, M., Bonnie, N., Budau, K., Goodman, D., ... Stoddart, J. (2020). Ontario Incidence Study of Reported Child Abuse and Neglect-2018 (OIS-2018). Child Welfare Research Portal. https://cwrp.ca/sites/default/files/publications/Ontario\%20Incidence\%20Study\%20of\%20Reported\%20Child\%20Abuse\%20a nd\%20Neglect\%202018.pdf

Firk, C., Dahmen, B., Lehmann, C., Herpertz-Dahlmann, B., \& Konrad, K. (2018). Down-regulation of amygdala response to infant crying: A role for distraction in maternal emotion regulation. Emotion, 18(3), 412-423. https://doi.org/10.1037/emo0000373

Fitzgerald, M. M., Shipman, K. L., Jackson, J. L., McMahon, R. J., \& Hanley, H. M. (2005). Perceptions of parenting versus parent-child interactions among incest survivors. Child Abuse \& Neglect, 296), 661-681. https://doi.org/10.1016/j.chiabu.2004.10.012

Florange, J. G., \& Herpertz, S. C. (2019). Parenting in patients with borderline personality disorder, sequelae for the offspring and approaches to treatment and prevention. Current Psychiatry Reports, 21(2). https://doi.org/10.1007/s11920-019-0996-1

Ford, J. D., Courtois, C. A., Steele, K., Hart, O. V. D., \& Nijenhuis, E. R. (2005). Treatment of complex posttraumatic self-dysregulation. Journal of Traumatic Stress, 18(5), 437-447. https://doi.org/10.1002/jts.20051

Freyd, J. J. (1996). Betrayal trauma: The logic of forgetting childhood abuse. Harvard University Press.

Friedlmeier, W., Corapci, F., \& Cole, P. M. (2011). Emotion socialization in cross-cultural perspective. Social and Personality Psychology Compass, 5(7), 410-427. https://doi.org/10.1111/j.1751-9004.2011.00362.x

Fuchs, A., Möhler, E., Resch, F., \& Kaess, M. (2015). Impact of a maternal history of childhood abuse on the development of motherinfant interaction during the first year of life. Child Abuse \& Neglect, 48, 179-189. https://doi.org/10.1016/j.chiabu.2015.05.023

Garwood, S. K., Gerassi, L., Jonson-Reid, M., Plax, K., \& Drake, B. (2015). More than poverty: The effect of child abuse and neglect on teen pregnancy risk. Journal of Adolescent Health, 57(2), 164-168. https://doi.org/10.1016/j.jadohealth.2015.05.004

Gerhardt, M., Feng, X., Wu, Q., Hooper, E. G., Ku, S., \& Chan, M. H. (2020). A naturalistic study of parental emotion socialization: Unique contributions of fathers. Journal of Family Psychology, 34(2), 204-214. https://doi.org/10.1037/fam0000602

Gibb, B. E., Schofield, C. A., \& Coles, M. E. (2009). Reported history of childhood abuse and young adults' information-processing biases for facial displays of emotion. Child Maltreatment, 14(2), 148-156. https://doi.org/10.1177/1077559508326358

Goldsmith, R. E., Chesney, S. A., Heath, N. M., \& Barlow, M. R. (2013). Emotion regulation difficulties mediate associations between betrayal trauma and symptoms of posttraumatic stress, depression, and anxiety. Journal of Traumatic Stress, 26(3), 376-384. https://doi.org/10.1002/jts.21819

Goldsmith, R. E., Freyd, J. J., \& DePrince, A. P. (2012). Betrayal trauma: Associations with psychological and physical symptoms in young adults. Journal of Interpersonal Violence, 273), 547-567. https://doi.org/10.1177/0886260511421672

Gottman, J. M., Katz, L. F., \& Hooven, C. (1996). Parental meta-emotion philosophy and the emotional life of families: Theoretical models and preliminary data. Journal of Family Psychology, 103), 243-268. https://doi.org/10.1037/0893-3200.10.3.243

Gratz, K. L., Bornovalova, M. A., Delany-Brumsey, A., Nick, B., \& Lejuez, C. W. (2007). A laboratory-based study of the relationship between childhood abuse and experiential avoidance among inner-city substance users: The role of emotional nonacceptance. Behavior Therapy, 38(3), 256-268. https://doi.org/10.1016/j.beth.2006.08.006

Gratz, K. L., Tull, M. T., Baruch, D. E., Bornovalova, M. A., \& Lejuez, C. W. (2008). Factors associated with co-occurring borderline personality disorder among inner-city substance users: The roles of childhood maltreatment, negative affect intensity/reactivity, and emotion dysregulation. Comprehensive Psychiatry, 49(6), 603-615. https://doi.org/10.1016/j.comppsych.2008.04.005

Gross, J. J., \& Jazaieri, H. (2014). Emotion, emotion regulation, and psychopathology: An affective science perspective. Clinical Psychological Science, 2(4), 387-401. https://doi.org/10.1177/2167702614536164

Han, Z. R., Qian, J., Gao, M., \& Dong, J. (2015). Emotion socialization mechanisms linking Chinese fathers', mothers', and children's emotion regulation: A moderated mediation model. Journal of Child and Family Studies, 24(12), $3570-3579$. https://doi.org/10.1007/s10826-015-0158-y

Harel, G., \& Finzi-Dottan, R. (2018). Childhood maltreatment and its effect on parenting among high-risk parents. Journal of Child and Family Studies, 275), 1513-1524. https://doi.org/10.1007/s10826-017-0994-z 
Hastings, P. D., Klimes-Dougan, B., Kendziora, K. T., Brand, A., \& Zahn-Waxler, C. (2014). Regulating sadness and fear from outside and within: Mothers' emotion socialization and adolescents' parasympathetic regulation predict the development of internalizing difficulties. Development and Psychopathology, 26(4pt2), 1369-1384. https://doi.org/10.1017/S0954579414001084

Havighurst, S., \& Harley, A. (2007a). Tuning in to kids: Emotionally intelligent parenting: Program manual. University of Melbourne.

Havighurst, S., \& Harley, A. (2007b). Tuning in to teens: Emotionally intelligent parenting: Program manual. University of Melbourne.

Havighurst, S. S., Kehoe, C. E., \& Harley, A. E. (2015). Tuning in to teens: Improving parental responses to anger and reducing youth externalizing behavior problems. Journal of Adolescence, 42, 148-158. https://doi.org/10.1016/j.adolescence.2015.04.005

Havighurst, S. S., Wilson, K. R., Harley, A. E., Kehoe, C., Efron, D., \& Prior, M. R. (2013). “Tuning into kids”: Reducing young children's behavior problems using an emotion coaching parenting program. Child Psychiatry \& Human Development, 44(2), $247-264$. https://doi.org/10.1007/s10578-012-0322-1

Havighurst, S. S., Wilson, K. R., Harley, A. E., Prior, M. R., \& Kehoe, C. (2010). Tuning in to kids: Improving emotion socialization practices in parents of preschool children-findings from a community trial. Journal of Child Psychology and Psychiatry, 51(12), 13421350. https://doi.org/10.1111/j.1469-7610.2010.02303.x

Heim, C., Newport, D. J., Heit, S., Graham, Y. P., Wilcox, M., Bonsall, R., Miller., A. H., \& Nemeroff, C. B. (2000). Pituitary-adrenal and autonomic responses to stress in women after sexual and physical abuse in childhood. JAMA, 284(5), $592-597$. https://doi.org/10.1001/jama.284.5.592

Heleniak, C., Jenness, J. L., Vander Stoep, A., McCauley, E., \& McLaughlin, K. A. (2016). Childhood maltreatment exposure and disruptions in emotion regulation: A transdiagnostic pathway to adolescent internalizing and externalizing psychopathology. Cognitive Therapy and Research, 40(3), 394-415. https://doi.org/10.1007/s10608-015-9735-z

Hillis, S. D., Anda, R. F., Dube, S. R., Felitti, V. J., Marchbanks, P. A., \& Marks, J. S. (2004). The association between adverse childhood experiences and adolescent pregnancy, long-term psychosocial consequences, and fetal death. Pediatrics, 113(2), 320-327. https://doi.org/10.1542/peds.113.2.320

Hopfinger, L., Berking, M., Bockting, C. L., \& Ebert, D. D. (2016). Emotion regulation mediates the effect of childhood trauma on depression. Journal of Affective Disorders, 198, 189-197. https://doi.org/10.1016/j.jad.2016.03.050

Huang, S., Trapido, E., Fleming, L., Arheart, K., Crandall, L., French, M., Malcolm, S., \& Prado, G. (2011). The long-term effects of childhood maltreatment experiences on subsequent illicit drug use and drug-related problems in young adulthood. Addictive Behaviors, 36(1-2), 95-102. https://doi.org/10.1016/j.addbeh.2010.09.001

Hughes, M., \& Cossar, J. (2016). The relationship between maternal childhood emotional abuse/neglect and parenting outcomes: A systematic review. Child Abuse Review, 25(1), 31-45. https://doi.org/10.1002/car.2393

Hughes, E. K., \& Gullone, E. (2010). Parent emotion socialisation practices and their associations with personality and emotion regulation. Personality and Individual Differences, 4977), 694-699. https://doi.org/10.1016/j.paid.2010.05.042

Hugill, M., Berry, K., \& Fletcher, I. (2017). The association between historical childhood sexual abuse and later parenting stress: A systematic review. Archives of Women's Mental Health, 20(2), 257-271. https://doi.org/10.1007/s00737-016-0708-3

Huh, H. J., Kim, K. H., Lee, H. K., \& Chae, J. H. (2017). The relationship between childhood trauma and the severity of adulthood depression and anxiety symptoms in a clinical sample: The mediating role of cognitive emotion regulation strategies. Journal of Affective Disorders, 213, 44-50. https://doi.org/10.1016/j.jad.2017.02.009

Hurrell, K. E., Hudson, J. L., \& Schniering, C. A. (2015). Parental reactions to children's negative emotions: Relationships with emotion regulation in children with an anxiety disorder. Journal of Anxiety Disorders, 29, $72-82$. https://doi.org/10.1016/j.janxdis.2014.10.008

Jones, J. D., Brett, B. E., Ehrlich, K. B., Lejuez, C. W., \& Cassidy, J. (2014). Maternal attachment style and responses to adolescents' negative emotions: The mediating role of maternal emotion regulation. Parenting, 14(3-4), $235-257$. https://doi.org/10.1080/15295192.2014.972760

Jones, S., Eisenberg, N., Fabes, R. A., \& MacKinnon, D. P. (2002). Parents' reactions to elementary school children's negative emotions: Relations to social and emotional functioning at school.Merrill-Palmer Quarterly, 48(2), $133-159$. https://doi.org/10.1353/mpq.2002.0007

Kaminski, J. W., Valle, L. A., Filene, J. H., \& Boyle, C. L. (2008). A meta-analytic review of components associated with parent training program effectiveness. Journal of Abnormal Child Psychology, 36(4), 567-589. https://doi.org/10.1007/s10802-007-9201-9

Katz, L. F., Shortt, J. W., Allen, N. B., Davis, B., Hunter, E., Leve, C., \& Sheeber, L. (2014). Parental emotion socialization in clinically depressed adolescents: Enhancing and dampening positive affect. Journal of Abnormal Child Psychology, 42(2), 205-215. https://doi.org/10.1007/s10802-013-9784-2

Kehoe, C. E., Havighurst, S. S., \& Harley, A. E. (2014). Tuning in to teens: Improving parent emotion socialization to reduce youth internalizing difficulties. Social Development, 23(2), 413-431. https://doi.org/10.1111/sode.12060 
Kessler, R. C., McLaughlin, K. A., Green, J. G., Gruber, M. J., Sampson, N. A., Zaslavsky, A. M., Aguilar-Gaxiola, S., Alhamzawi, A. O., Alonso, J., Angermeyer, M., Benjet, C., Bromet E., Chatterji, S., de Girolamo, G., Demyttenaere, K., Fayyad, J., Florescu, S., Gal, G., Gureje, O., ... \& Williams, D. R. (2010). Childhood adversities and adult psychopathology in the WHO World Mental Health Surveys. British Journal of Psychiatry, 1975), 378-385. https://doi.org/10.1192/bjp.bp.110.080499

Kiel, E. J., Viana, A. G., Tull, M. T., \& Gratz, K. L. (2017). Emotion socialization strategies of mothers with borderline personality disorder symptoms: The role of maternal emotion regulation and interactions with infant temperament. Journal of Personality Disorders, 31(3), 399-416. https://doi.org/10.1521/pedi_2016_30_256

Kim, J., \& Cicchetti, D. (2010). Longitudinal pathways linking child maltreatment, emotion regulation, peer relations, and psychopathology. Journal of Child Psychology and Psychiatry, 51(6), 706-716. https://doi.org/10.1111/j.1469-7610.2009.02202.x

Klimes-Dougan, B., Pearson, T. E., Jappe, L., Mathieson, L., Simard, M. R., Hastings, P., \& Zahn-Waxler, C. (2014). Adolescent emotion socialization: A longitudinal study of friends' responses to negative emotions. Social Development, 23(2), 395-412. https://doi.org/10.1111/sode.12045

Kooiman, C. G., van Rees Vellinga, S., Spinhoven, P., Draijer, N., Trijsburg, R. W., \& Rooijmans, H. G. (2004). Childhood adversities as risk factors for alexithymia and other aspects of affect dysregulation in adulthood. Psychotherapy and Psychosomatics, 73(2), 107116. https://doi.org/10.1159/000075542

Lagacé-Séguin, D. G., \& Coplan, R. J. (2005). Maternal emotional styles and child social adjustment: Assessment, correlates, outcomes and goodness of fit in early childhood. Social Development, 14(4), $613-635$. https://doi.org/10.1111/j.1467-9507.2005.00320.x

Larson, R. W., Moneta, G., Richards, M. H., \& Wilson, S. (2002). Continuity, stability, and change in daily emotional experience across adolescence. Child Development, 73(4), 1151-1165. https://doi.org/10.1111/1467-8624.00464

Le, B. M., \& Impett, E. A. (2016). The costs of suppressing negative emotions and amplifying positive emotions during parental caregiving. Personality and Social Psychology Bulletin, 42(3), 323-336. https://doi.org/10.1177/0146167216629122

Leeb, R., Paulozzi, L., Melanson, C., Simon, T., \& Arias, I. (2008). Child maltreatment surveillance: Uniform definitions for public health and recommended data elements (version 1.0). Centers for Disease Control and Prevention, National Center for Injury Prevention and Control.

Letourneau, N. L., Duffett-Leger, L., Levac, L., Watson, B., \& Young-Morris, C. (2013). Socioeconomic status and child development: A meta-analysis. Journal of Emotional and Behavioral Disorders, 21(3), 211-224. https://doi.org/10.1177/1063426611421007

Li, D., Li, D., Wu, N., \& Wang, Z. (2019). Intergenerational transmission of emotion regulation through parents' reactions to children's negative emotions: Tests of unique, actor, partner, and mediating effects. Children and Youth Services Review, 101, 113-122. https://doi.org/10.1016/j.childyouth.2019.03.038

Linehan, M. (1993). Cognitive-behavioral treatment of borderline personality disorder. Guilford Press.

Liu, S., Zhou, N., Dong, S., Wang, Z., \& Hao, Y. (2019). Maternal childhood emotional abuse predicts Chinese infant behavior problems: Examining mediating and moderating processes. Child Abuse \& Neglect, 88, $307-316$. https://doi.org/10.1016/j.chiabu.2018.12.006

Locke, T. F., \& Newcomb, M. (2004). Child maltreatment, parent alcohol-and drug-related problems, polydrug problems, and parenting practices: A test of gender differences and four theoretical perspectives. Journal of Family Psychology, 18(1), 120134. https://doi.org/10.1037/0893-3200.18.1.120

Lunkenheimer, E. S., Shields, A. M., \& Cortina, K. S. (2007). Parental emotion coaching and dismissing in family interaction. Social Development, 16(2), 232-248. https://doi.org/10.1111/j.1467-9507.2007.00382.x

Lyons-Ruth, K., \& Block, D. (1996). The disturbed caregiving system: Relations among childhood trauma, maternal caregiving, and infant affect and attachment. Infant Mental Health Journal, 17(3), $257-275$. https://doi.org/10.1002/(SICI)1097-0355(199623)17:3<257::AID-IMHJ5>3.0.CO;2-L

Madigan, S., Wade, M., Plamondon, A., Vaillancourt, K., Jenkins, J. M., Shouldice, M., \& Benoit, D. (2014). Course of depression and anxiety symptoms during the transition to parenthood for female adolescents with histories of victimization. Child Abuse \& Neglect, 38(7), 1160-1170. https://doi.org/10.1016/j.chiabu.2014.04.002

Maguire, S., \& Naughton, A. (2016). Neglect: Widespread, damaging and difficult to identify. Paediatrics and Child Health, 26(11), 485487. https://doi.org/10.1016/j.paed.2016.06.010

Maliken, A. C., \& Katz, L. F. (2013). Exploring the impact of parental psychopathology and emotion regulation on evidence-based parenting interventions: A transdiagnostic approach to improving treatment effectiveness. Clinical Child and Family Psychology Review, 16(2), 173-186. https://doi.org/10.1007/s10567-013-0132-4

Martin, C. G., Kim, H. K., \& Freyd, J. J. (2018). Overwhelmed by emotion: Pathways from revictimization to mothers' negative emotional responsivity. Family Process, 57(4), 947-959. https://doi.org/10.1111/famp.12339 
Marysko, M., Reck, C., Mattheis, V., Finke, P., Resch, F., \& Moehler, E. (2010). History of childhood abuse is accompanied by increased dissociation in young mothers five months postnatally. Psychopathology, 43(2), 104-109. https://doi.org/10.1159/000276999

Masten, C. L., Guyer, A. E., Hodgdon, H. B., McClure, E. B., Charney, D. S., Ernst, M., Kaufman, J., Pine, D. S., \& Monk, C. S. (2008). Recognition of facial emotions among maltreated children with high rates of post-traumatic stress disorder. Child Abuse \& Neglect, 32(1), 139-153. https://doi.org/10.1016/j.chiabu.2007.09.006

Maughan, A., \& Cicchetti, D. (2002). Impact of child maltreatment and interadult violence on children's emotion regulation abilities and socioemotional adjustment. Child Development, 73(5), 1525-1542. https://doi.org/10.1111/1467-8624.00488

Mazzone, S., \& Nader-Grosbois, N. (2017). Variability and predictors of mothers and fathers' socialization behaviors and bidirectional links with their preschoolers socio-emotional competences. Journal of Behavioral and Brain Science, 712), 621-653. https://doi.org/10.4236/jbbs.2017.712043

McCloskey, L. A. (2017). The intergenerational transmission of child maltreatment: Socio-ecological and psychological origins of maternal risk. In D. M. Teti (Ed.). Parenting and family processes in child maltreatment and intervention (pp. 47-76). Springer, Cham. https://doi.org/10.1007/978-3-319-40920-7_4

McCullough, C., Han, Z. R., Morelen, D., \& Shaffer, A. (2015). The moderating effects of maternal age at childbirth and emotion dysregulation on the intergenerational continuity of emotionally unsupportive parenting behaviors. Journal of Family Issues, 38(7), 948-971. https://doi.org/10.1177/0192513X15597290

McCullough, C., Harding, H. G., Shaffer, A., Han, R. Z., \& Bright, M. (2014). Intergenerational continuity of risky parenting: A personoriented approach to assessing parenting behaviors. Journal of Family Violence, 29(4), $409-418$. https://doi.org/10.1007/s10896-014-9593-6

McDonald, S. W., Madigan, S., Racine, N., Benzies, K., Tomfohr, L., \& Tough, S. (2019). Maternal adverse childhood experiences, mental health, and child behaviour at age 3: The all our families community cohort study. Preventive Medicine, 118, $286-294$. https://doi.org/10.1016/j.ypmed.2018.11.013

McElwain, N. L., Halberstadt, A. G., \& Volling, B. L. (2007). Mother-and father-reported reactions to children's negative emotions: Relations to young children's emotional understanding and friendship quality. Child Development, 78(5), $1407-1425$. https://doi.org/10.1111/j.1467-8624.2007.01074.x

McQuade, J. D., \& Breaux, R. P. (2017). Parent emotion socialization and pre-adolescent's social and emotional adjustment: Moderating effects of autonomic nervous system reactivity. Biological Psychology, 130, 67-76. https://doi.org/10.1016/j.biopsycho.2017.10.007

Messman-Moore, T. L., Walsh, K. L., \& DiLillo, D. (2010). Emotion dysregulation and risky sexual behavior in revictimization. Child Abuse \& Neglect, 34(12), 967-976. https://doi.org/10.1016/j.chiabu.2010.06.004

Meyer, S., Raikes, H. A., Virmani, E. A., Waters, S., \& Thompson, R. A. (2014). Parent emotion representations and the socialization of emotion regulation in the family. International Journal of Behavioral Development, 38(2) 164-173. https://doi.org/10.1177/0165025413519014

Mielke, E. L., Neukel, C., Bertsch, K., Reck, C., Möhler, E., \& Herpertz, S. C. (2016). Maternal sensitivity and the empathic brain: Influences of early life maltreatment. Journal of Psychiatric Research, 77, 59-66. https://doi.org/10.1016/j.jpsychires.2016.02.013

Miller, R. L., Dunsmore, J. C., \& Smith, C. L. (2015). Effortful control and parents' emotion socialization patterns predict children's positive social behavior: A person-centered approach. Early Education and Development, 26(2), 167-188. https://doi.org/10.1080/10409289.2015.975034

Miller-Slough, R., \& Dunsmore, J. C. (2019). Longitudinal patterns in parent and friend emotion socialization: Associations with adolescent emotion regulation. Journal of Research on Adolescence, 2944), 953-966. https://doi.org/10.1111/jora.12434

Miller-Slough, R. L., \& Dunsmore, J. C. (2016). Parent and friend emotion socialization in adolescence: Associations with psychological adjustment. Adolescent Research Review, 1(4), 287-305. https://doi.org/10.1007/s40894-016-0026-z

Miller-Slough, R. L., Dunsmore, J. C., Zeman, J. L., Sanders, W. M., \& Poon, J. A. (2018). Maternal and paternal reactions to child sadness predict children's psychosocial outcomes: A family-centered approach. Social Development, 27(3), $495-509$. https://doi.org/10.1111/sode.12244

Miller-Slough, R., Zeman, J. L., Poon, J. A., \& Sanders, W. M. (2016). Children's maternal support-seeking: Relations to maternal emotion socialization responses and children's emotion management. Journal of Child and Family Studies, 25(10), $3009-3021$. https://doi.org/10.1007/s10826-016-0465-y

Moehler, E., Biringen, Z., \& Poustka, L. (2007). Emotional availability in a sample of mothers with a history of abuse. American Journal of Orthopsychiatry, 774), 624-628. https://doi.org/10.1037/0002-9432.77.4.624

Mollborn, S., \& Morningstar, E. (2009). Investigating the relationship between teenage childbearing and psychological distress using longitudinal evidence. Journal of Health and Social Behavior, 503), 310-326. https://doi.org/10.1177/002214650905000305 
Morelen, D., Shaffer, A., \& Suveg, C. (2016). Maternal emotion regulation: Links to emotion parenting and child emotion regulation. Journal of Family Issues, 37(13), 1891-1916. https://doi.org/10.1177/0192513X14546720

Morelen, D., \& Suveg, C. (2012). A real-time analysis of parent-child emotion discussions: The interaction is reciprocal. Journal of Family Psychology, 26(6), 998-1003. https://doi.org/10.1037/a0030148

Moretti, M. M., \& Craig, S. G. (2013). Maternal versus paternal physical and emotional abuse, affect regulation and risk for depression from adolescence to early adulthood. Child Abuse \& Neglect, 371), 4-13. https://doi.org/10.1016/j.chiabu.2012.09.015

Morris, C. A., Denham, S. A., Bassett, H. H., \& Curby, T. W. (2013). Relations among teachers' emotion socialization beliefs and practices and preschoolers' emotional competence. Early Education \& Development, 24(7), 979-999. https://doi.org/10.1080/10409289.2013.825186

Morris, A. S., Silk, J. S., Steinberg, L., Myers, S. S., \& Robinson, L. R. (2007). The role of the family context in the development of emotion regulation. Social Development, 16(2), 361-388. https://doi.org/10.1111/j.1467-9507.2007.00389.x

Muller, R. T., Vascotto, N. A., Konanur, S., \& Rosenkranz, S. (2013). Emotion regulation and psychopathology in a sample of maltreated children. Journal of Child \& Adolescent Trauma, 6(1), 25-40. https://doi.org/10.1080/19361521.2013.737441

Muzik, M., Ads, M., Bonham, C., Lisa Rosenblum, K., Broderick, A., \& Kirk, R. (2013). Perspectives on trauma-informed care from mothers with a history of childhood maltreatment: A qualitative study. Child Abuse \& Neglect, 3712), $1215-1224$. https://doi.org/10.1016/j.chiabu.2013.07.014

Muzik, M., Bocknek, E. L., Broderick, A., Richardson, P., Rosenblum, K. L., Thelen, K., \& Seng, J. S. (2013). Mother-infant bonding impairment across the first 6 months postpartum: The primacy of psychopathology in women with childhood abuse and neglect histories. Archives of Women's Mental Health, 16(1), 29-38. https://doi.org/10.1007/s00737-012-0312-0

Muzik, M., McGinnis, E. W., Bocknek, E., Morelen, D., Rosenblum, K. L., Liberzon, I., Seng, J., \& Abelson, J. L. (2016). PTSD symptoms across pregnancy and early postpartum among women with lifetime PTSD diagnosis. Depression and Anxiety, 33(7), 584-591. https://doi.org/10.1002/da.22465

Neukel, C., Bertsch, K., Fuchs, A., Zietlow, A. L., Reck, C., Moehler, E., Brunner., R., Bermpohl, F., \& Herpertz, S. C. (2018). The maternal brain in women with a history of early-life maltreatment: An imagination-based fMRI study of conflictual versus pleasant interactions with children. Journal of Psychiatry and Neuroscience, 43(4), 273-282. https://doi.org/10.1503/jpn.170026

Nyström-Hansen, M., Andersen, M. S., Khoury, J. E., Davidsen, K., Gumley, A., Lyons-Ruth, K., Macbeth, A., \& Harder, S. (2019). Hair cortisol in the perinatal period mediates associations between maternal adversity and disrupted maternal interaction in early infancy. Developmental Psychobiology, 61(4), 543-556. https://doi.org/10.1002/dev.21833

O'Neal, C. R., \& Magai, C. (2005). Do parents respond in different ways when children feel different emotions? The emotional context of parenting. Development and Psychopathology, 17(2), 467-487. https://doi.org/10.1017/S0954579405050224

Pereira, J., Vickers, K., Atkinson, L., Gonzalez, A., Wekerle, C., \& Levitan, R. (2012). Parenting stress mediates between maternal maltreatment history and maternal sensitivity in a community sample. Child Abuse \& Neglect, 36(5), $433-437$. https://doi.org/10.1016/j.chiabu.2012.01.006

Perlman, S. B., Kalish, C. W., \& Pollak, S. D. (2008). The role of maltreatment experience in children's understanding of the antecedents of emotion. Cognition \& Emotion, 22(4), 651-670. https://doi.org/10.1080/02699930701461154

Plant, D. T., Pawlby, S., Pariante, C. M., \& Jones, F. W. (2018). When one childhood meets another - maternal childhood trauma and offspring child psychopathology: A systematic review. Clinical Child Psychology and Psychiatry, 23(3), 483-500. https://doi.org/10.1177/1359104517742186

Pollak, S. D., Cicchetti, D., Hornung, K., \& Reed, A. (2000). Recognizing emotion in faces: developmental effects of child abuse and neglect. Developmental Psychology, 36(5), 679-688. https://doi.org/10.1037//0012-1649.36.5.679

Poon, J., Zeman, J., Miller-Slough, R., Sanders, W., \& Crespo, L. (2017). "Good enough" parental responsiveness to children's sadness: Links to psychosocial functioning. Journal of Applied Developmental Psychology, 48, 69-78. https://doi.org/10.1016/j.appdev.2016.11.005

Rea, H. M., \& Shaffer, A. (2016). Expressed emotion in mothers of school-age children: Relations to maternal maltreatment and parenting behavior. Journal of Child and Family Studies, 25(12), 3749-3759. https://doi.org/10.1007/s10826-016-0500-z

Ringeisen, H., Casanueva, C. E., Urato, M., \& Stambaugh, L. F. (2009). Mental health service use during the transition to adulthood for adolescents reported to the child welfare system. Psychiatric Services, 60(8), 1084-1091. https://doi.org/10.1176/ps.2009.60.8.1084

Rosenthal, M. Z., Hall, M. L. R., Palm, K. M., Batten, S. V., \& Follette, V. M. (2005). Chronic avoidance helps explain the relationship between severity of childhood sexual abuse and psychological distress in adulthood. Journal of Child Sexual Abuse, 14(4), 2541. https://doi.org/10.1300/J070v14n04_02 
Roustit, C., Renahy, E., Guernec, G., Lesieur, S., Parizot, I., \& Chauvin, P. (2009). Exposure to interparental violence and psychosocial maladjustment in the adult life course: advocacy for early prevention. Journal of Epidemiology \& Community Health, 63(7), 563-568. https://doi.org/10.1136/jech.2008.077750

Rutherford, H. J., Wallace, N. S., Laurent, H. K., \& Mayes, L. C. (2015). Emotion regulation in parenthood. Developmental Review, 36, 114. https://doi.org/10.1016/j.dr.2014.12.008

Sanders, W., Zeman, J., Poon, J., \& Miller, R. (2015). Child regulation of negative emotions and depressive symptoms: The moderating role of parental emotion socialization. Journal of Child and Family Studies, 24, 402-415. https://doi.org/10.1007/s10826-0139850-y

Schelbe, L., \& Geiger, J. M. (2017). What is intergenerational transmission of child maltreatment? In L. Schelbe \& J. M. Geiger (Eds.), Intergenerational transmission of child maltreatment (pp. 1-14). Springer International Publishing. https://doi.org/10.1007/978-3-319-43824-5_1

Schuetze, P., \& Eiden, R. D. (2005). The relationship between sexual abuse during childhood and parenting outcomes: Modeling direct and indirect pathways. Child Abuse \& Neglect, 296), 645-659. https://doi.org/10.1016/j.chiabu.2004.11.004

Schore, A. N. (2002). Dysregulation of the right brain: a fundamental mechanism of traumatic attachment and the psychopathogenesis of posttraumatic stress disorder. Australian and New Zealand Journal of Psychiatry, 36(1), 9-30. https://doi.org/10.1046/j.1440-1614.2002.00996.x

Schore, J. R., \& Schore, A. N. (2008). Modern attachment theory: The central role of affect regulation in development and treatment. Clinical Social Work Journal, 36(1), 9-20. https://doi.org/10.1007/s10615-007-0111-7

Serbin, L. A., \& Karp, J. (2004). The intergenerational transfer of psychosocial risk: Mediators of vulnerability and resilience. Annual Review of Psychology, 55, 333-363. https://doi.org/10.1146/annurev.psych.54.101601.145228

Sexton, M. B., Davis, M. T., Menke, R., Raggio, G. A., \& Muzik, M. (2017). Mother-child interactions at six months postpartum are not predicted by maternal histories of abuse and neglect or maltreatment type. Psychological Trauma: Theory, Research, Practice, and Policy, 95), 622-626. https://doi.org/10.1037/tra0000272

Shackman, J. E., \& Pollak, S. D. (2014). Impact of physical maltreatment on the regulation of negative affect and aggression. Development and Psychopathology, 26(4pt1), 1021-1033. https://doi.org/10.1017/S0954579414000546

Shaffer, A., Suveg, C., Thomassin, K., \& Bradbury, L. L. (2012). Emotion socialization in the context of family risks: Links to child emotion regulation. Journal of Child and Family Studies, 21(6), 917-924. https://doi.org/10.1007/s10826-011-9551-3

Shipman, K., Edwards, A., Brown, A., Swisher, L., \& Jennings, E. (2005). Managing emotion in a maltreating context: A pilot study examining child neglect. Child Abuse \& Neglect, 299), 1015-1029. https://doi.org/10.1016/j.chiabu.2005.01.006

Shipman, K. L., Schneider, R., Fitzgerald, M. M., Sims, C., Swisher, L., \& Edwards, A. (2007). Maternal emotion socialization in maltreating and non-maltreating families: Implications for children's emotion regulation. Social Development, 16(2), $268-285$. https://doi.org/10.1111/j.1467-9507.2007.00384.x

Shipman, K. L., \& Zeman, J. (1999). Emotional understanding: A comparison of physically maltreating and nonmaltreating motherchild dyads. Journal of Clinical Child and Adolescent Psychology, 28(3), $407-417$. https://doi.org/10.1207/S15374424jccp280313

Shipman, K. L., \& Zeman, J. (2001). Socialization of children's emotion regulation in mother-child dyads: A developmental psychopathology perspective. Development and Psychopathology, 13(2), $317-336$. https://doi.org/10.1017/S0954579401002073

Shipman, K., Zeman, J., Penza, S., \& Champion, K. (2000). Emotion management skills in sexually maltreated and nonmaltreated girls: A developmental psychopathology perspective. Development and Psychopathology, 12(1), 47-62. https://doi.org/10.1017/S0954579400001036

Shortt, J. W., Katz, L. F., Allen, N. B., Leve, C., Davis, B., \& Sheeber, L. B. (2016). Emotion socialization in the context of risk and psychopathology: Mother and father socialization of anger and sadness in adolescents with depressive disorder. Social Development, 25(1), 27-46. https://doi.org/10.1111/sode.12138

Spencer, M. S., Kalil, A., Larson, N. C., Spieker, S. J., \& Gilchrist, L. D. (2002). Multigenerational coresidence and childrearing conflict: Links to parenting stress in teenage mothers across the first two years postpartum. Applied Developmental Science, 6(3), 157170. https://doi.org/10.1207/S1532480XADS0603_5

Statistics Canada (2019). Population estimates, quarterly (Table 17-10-00009-01) [Data set]. https://doi.org/10.25318/1710000901-eng

Steinberg, L. (2005). Cognitive and affective development in adolescence. Trends in Cognitive Sciences, 9(2), 69-74. https://doi.org/10.1016/j.tics.2004.12.005 
Stepp, S. D., Whalen, D. J., Pilkonis, P. A., Hipwell, A. E., \& Levine, M. D. (2012). Children of mothers with borderline personality disorder: Identifying parenting behaviors as potential targets for intervention. Personality Disorders: Theory, Research, and Treatment, 3(1), 76-91. https://doi.org/10.1037/a0023081

Stocker, C. M., Richmond, M. K., Rhoades, G. K., \& Kiang, L. (2007). Family emotional processes and adolescents' adjustment. Social Development, 16(2), 310-325. https://doi.org/10.1111/j.1467-9507.2007.00386.x

Suveg, C., Sood, E., Barmish, A., Tiwari, S., Hudson, J. L., \& Kendall, P. C. (2008). " I'd rather not talk about it": Emotion parenting in families of children with an anxiety disorder. Journal of Family Psychology, 22(6), 875-884. https://doi.org/10.1037/a0012861

Talmon, A., Horovitz, M., Shabat, N., Haramati, O. S., \& Ginzburg, K. (2019). "Neglected moms" - The implications of emotional neglect in childhood for the transition to motherhood. Child Abuse \& Neglect, 88, $445-454$. https://doi.org/10.1016/j.chiabu.2018.12.021

Thomas, R., DiLillo, D., Walsh, K., \& Polusny, M. A. (2011). Pathways from child sexual abuse to adult depression: The role of parental socialization of emotions and alexithymia. Psychology of Violence, 1(2), 121-135. https://doi.org/10.1037/a0022469

Thompson-Booth, C., Viding, E., Mayes, L. C., Rutherford, H. J., Hodsoll, S., \& McCrory, E. J. (2014). Here's looking at you, kid: Attention to infant emotional faces in mothers and non-mothers. Developmental Science, 171), 35-46. https://doi.org/10.1111/desc.12090

Trickett, P. K., Noll, J. G., \& Putnam, F. W. (2011). The impact of sexual abuse on female development: Lessons from a multigenerational, longitudinal research study. Development and Psychopathology, 23(2), 453-476. https://doi.org/10.1017/S0954579411000174

Vaillancourt, K., Pawlby, S., \& Fearon, R. P. (2017). History of childhood abuse and mother-infant interaction: A systematic review of observational studies. Infant Mental Health Journal, 38(2), 226-248. https://doi.org/10.1002/imhj.21634

Valiente, C., Fabes, R. A., Eisenberg, N., \& Spinrad, T. L. (2004). The relations of parental expressivity and support to children's coping with daily stress. Journal of Family Psychology, 18(1), 97-106. https://doi.org/10.1037/0893-3200.18.1.97

Valiente, C., Lemery-Chalfant, K., \& Reiser, M. (2007). Pathways to problem behaviors: Chaotic homes, parent and child effortful control, and parenting. Social Development, 16(2), 249-267. https://doi.org/10.1111/j.1467-9507.2007.00383.x

van den Berg, L. J. M., Tollenaar, M. S., Compier-de Block, L. H. C. G., Bakermans-Kranenburg, M. J., \& Elzinga, B. M. (2019). An intergenerational family study on the impact of experienced and perpetrated child maltreatment on neural face processing. Psychoneuroendocrinology, 103, 266-275. https://doi.org/10.1016/j.psyneuen.2019.01.030

van der Kolk, B. A. (2005). Developmental trauma disorder: Toward a rational diagnosis for children with complex trauma histories. Psychiatric Annals, 35(5), 401-408. https://doi.org/10.3928/00485713-20050501-06

van der Kolk, B. A. (1996). The complexity of adaptation to trauma: Self-regulation, stimulus discrimination, and characterological development. In B. A. van der Kolk, A. C. McFarlane, \& L. Weisaeth (Eds.), Traumatic stress: The effects of overwhelming experience on mind, body, and society (pp. 182-213). Guilford Press.

van Voorhees, E., \& Scarpa, A. (2004). The effects of child maltreatment on the hypothalamic-pituitary-adrenal axis. Trauma, Violence, \& Abuse, 5(4), 333-352. https://doi.org/10.1177/1524838004269486

Walsh, K., DiLillo, D., \& Scalora, M. J. (2011). The cumulative impact of sexual revictimization on emotion regulation difficulties: An examination of female inmates. Violence Against Women, 178), 1103-1118. https://doi.org/10.1177/1077801211414165

Wark, J., \& Vis, J. A. (2018). Effects of child sexual abuse on the parenting of male survivors. Trauma, Violence, and Abuse, 19(5), 499511. https://doi.org/10.1177/1524838016673600

Weich, S., Patterson, J., Shaw, R., \& Stewart-Brown, S. (2009). Family relationships in childhood and common psychiatric disorders in later life: systematic review of prospective studies. British Journal of Psychiatry, 194(5), $392-398$. https://doi.org/10.1192/bjp.bp.107.042515

Williams, S. R., \& Woodruff-Borden, J. (2015). Parent emotion socialization practices and child self-regulation as predictors of child anxiety: The mediating role of cardiac variability. Child Psychiatry \& Human Development, 46(4), $512-522$. https://doi.org/10.1007/s10578-014-0492-0

Yap, M. B., Allen, N. B., Leve, C., \& Katz, L. F. (2008). Maternal meta-emotion philosophy and socialization of adolescent affect: The moderating role of adolescent temperament. Journal of Family Psychology, 22(5), 688-700. https://doi.org/10.1037/a0013104

Zeman, J., Cassano, M., \& Adrian, M. (2013). Socialization influences on children's and adolescent's emotional self-regulation processes: A developmental psychopathology perspective. In K. C. Barrett, N. A. Fox, G. A. Morgan, D. J. Fidler, \& L. A. Daunhauer (Eds.), Handbook of self-regulatory processes in development: New directions and international perspectives (pp. 79-106). Psychology Press. https://doi.org/10.4324/9780203080719.ch5

Zeman, J., Perry-Parrish, C., \& Cassano, M. (2010). Parent-child discussions of anger and sadness: The importance of parent and child gender during middle childhood. New Directions for Child and Adolescent Development, 2010(128), 65-83. https://doi.org/10.1002/cd.269 
Zvara, B. J., Meltzer-Brody, S., Mills-Koonce, W. R., Cox, M., \& The Family Life Project Key Investigators (2017). Maternal childhood sexual trauma and early parenting: Prenatal and postnatal associations. Infant and Child Development, 26(3), e1991, https://doi.org/10.1002/icd.1991

Zvara, B. J., Mills-Koonce, R., \& Cox, M. (2017). Maternal childhood sexual trauma, child directed aggression, parenting behavior, and the moderating role of child sex. Journal of Family Violence, 32(2), 219-229. https://doi.org/10.1007/s10896-016-9839-6 